\title{
UNA PROPUESTA PARA LA INTEGRACIÓN CURRICULAR DE LAS ÁREAS DE LENGUA CASTELLANA E INGLÉS EN EL CURRICULO DE ENSEÑANZA BILINGÜE PARA LA ESO
}

\author{
Víctor Cantero García
}

Universidad de Sevilla

\section{RESUMEN}

En este artículo su autor nos presenta una ejemplificación curricular correspondiente a la integración en el CLIL (Curriculum Integrado de las Lenguas) de las Áreas de Lengua Castellana y Literatura e Inglés de la ESO. Basado en su experiencia como Coordinador de Sección Bilingüe en IES, el colaborador pretende aportar un modelo de Programación Didáctica que sea de utilidad para todos los docentes que desarrollan su labor en las Secciones Bilingües. Esta ejemplificación curricular está fundamentada en los principios de competencia comunicativa y de mediación lingüística que se establecen en las directrices del Marco Común Europeo de Referencia de las Lenguas y en modo alguno está cerrada; antes bien, constituye uno de los documentos básicos cuya puesta en práctica irá contribuyendo a la redacción definitiva del Curriculum Integrado de la Sección Bilingüe de nuestro IES.

Palabras clave: Enseñanza bilingüe, competencia comunicativa, curriculum integrado de las lenguas, plurilingüismo, ejemplificación curricular.

\section{ABSTRACT}

This article deals with an integrated language and content aproach in our bilingual classes for the Compulsory Secondary Education. Here there are some guidelines, stretegies and techniques for midle and high school language and content teachers who wish to use an integrated aproach between Spanish Language and English in their lessons.

The author emphasizes on how the knowledge of linguistic skills on his/her mother tongue (Spanish) can help our students in the process of learning a second language, (English). It is only one ejample in order to make English language input as comprehensible as possible. The focus of this exemplification should be motivated by the content to be learned which will help identify the language 
skills requiered to learn that content, and the reasoning abilities needed to manipulate it.

Key words: Bilingual education, linguistic skills, plurilinguism, curriculum, integrated language and content.

\section{A modo de Introducción: con buenas intenciones y lo mejor posible fundadas}

Cuando el autor de este artículo asumió el reto de plasmar por escrito su iniciativa de ejemplificación correspondiente a la integración en el CLIL de las áreas de Lengua Castellana y Literatura e Inglés para la ESO es cuando entendió que era el momento oportuno para buscar argumentos con los que defender los beneficios de la enseñanza bilingüe ante la Comunidad Educativa del IES en el que se ubica nuestra Sección Bilingüe. Por ello creo oportuno iniciar mi colaboración exponiendo al lector el resultado de aquellas reflexiones previas, sin las cuales la presente propuesta de enseñanza bilingüe en la ESO no hubiera prosperado.

Pues bien, en el establecimiento de las bases de nuestro proyecto educativo bilingüe hemos de remontarnos a los orígenes del denominado movimiento CLIL (Curriculum Integrado de Contenidos y Lenguas) o en su caso AICLE ( Aprendizaje Integrado de Contenidos Curriculares y Lenguas Extranjeras). Tal como nos recuerda Almudena Fernández Fontecha (2001, p. 218) el origen de estas metodologías bilingües se remonta a las recomendaciones que la Comisión Europea hace a los Estados miembros en el Libro Blanco de la Educación, (1995) en el sentido de que desarrollen una política a favor del plurilinguismo y del multilinguismo. Esas recomendaciones sugieren a los gobernantes que introduzcan en sus países de forma urgente métodos de enseñanza que integren las lenguas y los contenidos extralingüísticos, pues por medio de esta integración se favorecen aspectos esenciales del proceso de enseñanza aprendizaje tales como procurar al alumno un aprendizaje más significativo, el incremento de su autonomía personal y de su motivación hacia el estudio. En otras palabras, estamos hablando de potenciar los objetivos básicos que se establecen en las finalidades educativas de la LOE para la Educación Secundaria Obligatoria.

Y estas sugerencias que las autoridades de la U.E. hacen a los estados miembros no pretenden sino trasladar a los mismos los buenos resultados que han venido dando desde hace años los programas educativos bilingües en países pioneros en este tipo de experiencias lingüísticas, tales como Canadá, USA o Finlandia, entre otros. En definitiva se trata de acomodar un modelo que viene siendo exitoso en otras latitudes, y que tal como sostiene María Luz Suárez, (2007, p.1): "viene siendo demando en Europa de forma creciente desde los años 90, tanto en los niveles de enseñanza primaria y secundaria como en la universidad, pues con ello se ponen en práctica las medidas sociopolíticas para el fomento de la integración europea que se determinan en el documento comunitario:"Teaching and learning. Towards the learning society".

Contando con tantos respaldos oficiales no era cuestión de perder el tren de la modernización y de la puesta a punto de los métodos de enseñanza y aprendizaje de las lenguas extranjeras que se aplican en los IES y estábamos dispuestos a aplicar en nuestro Centro un proyecto educativo de enseñanza bilingüe o enseñanza de contenidos a 
través de la L2. Tomada la decisión, ahora venía la parte más delicada pues se trataba de identificar el modelo de CLIL que mejor se adecuaba a nuestras peculiaridades, demostrar las ventajas concretas de ese modelo y aportar opiniones de voces autorizadas que respaldasen nuestra elección; en resumen, se trataba de poner de manifiesto lo que Donna M. Brinton (1988 p. 533) entiende que son los objetivos de la enseñanza de las segundas lenguas por medio de contenidos curriculares: "integrate better the reading, writing, and study skills required for academic success".

Comencemos pues por delimitar el tipo de CLIL que vamos a utilizar en nuestra propuesta de Integración Curricular de la L1 y L2, tarea para la cual hemos de comenzar por conocer los tipos existentes, las diferencias que existen entre ellos en cuanto a los contenidos a enseñar, su propósito final, su formato, las responsabilidades que el profesor adquiere en cada caso, el nivel educativo del alumno al que se le aplica y el modelo de evaluación que se pone en práctica. Matices al margen, Brinton y otros (2000, p. 6) en su obra Content-Based College ESL Instructions establecen tres claras modalidades de enseñanza por contenidos a través de L2:

a) Sheltered subject matter teaching.

b) Adjunct model.

c) Theme-based language instruction.

En nuestro caso es la primera la que mejor encaja con nuestros propósitos, pues en las Secciones Bilingües se trata de enseñar determinadas áreas curriculares previamente seleccionadas como Matemáticas, Ciencias Sociales, Música o Educación Física por medio de la L2. Ello no es obstáculo para que tomemos nota de las otras dos, pues en las tres modalidades existe un denominador común tal como sostiene M. Met (1998, p.7): " los tres tipos ofrecen un continum que va desde el más orientado hacia la enseñanza de contenidos extralingüísticos por medio de la L2 hasta aquellos que están diseñados para una enseñanza más directa de la L2 como lengua extranjera".

Sin embargo, optar por un tipo de CLIL no supone que tengamos claro lo que su aplicación comporta. Por ello, antes de adoptarlo como opción definitiva creí que era conveniente conocer las diferencias que D. March, ( 2000, pp. 1-2) establece entre lo que se entiende por "adquirir" y/o "aprender" una lengua. Está claro -señala March- que la "adquisición" de una lengua es un proceso natural que le viene dado al niño por el medio familiar y social en el que nace y se desarrolla en los primeros años; mientras que un "aprendizaje" reglado de un idioma por un adolescente o un adulto es un proceso que implica esfuerzo que nada tiene que ver con la adquisición natural, pues se trata de asimilar un nuevo código lingüístico que resulta extraño a nuestro entorno vital. Esta diferencia notoria entre "adquirir" y "aprender" es rentabilizada por los partidarios del método CLIL: M.A. Mohan, (1986); S. D. Krashen, (1999); G. Fruffauf., D. Coyle y I. Christ, (1996) o D. March y G. Langé, (1999). Todos ellos apuestan por un modelo del CLIL que se base en un método natural de aprendizaje de las lenguas; es decir: en la recepción del llamado "baño de lenguas" o la inmersión durante el mayor tiempo posible del alumno en dicho idioma en situaciones que tengan clara vinculación con su vida real. Un proceso que está muy claro para Krashen (1999, p.3), quien sostiene que "los programas bilingües proporcionan a los alumnos la información y los conocimientos que les son comprensibles en la L2 por medio de una enseñanza los más natural y gradual de dicha L2". 
Estas aclaraciones de los expertos contribuyen a disipar nuestras posibles dudas sobre las bondades del modelo CLIL seleccionado, pero no son suficientes para lanzarnos a comenzar esta experiencia educativa bilingüe. Aún nos quedan cuestiones por contestar: ¿qué conseguiremos con la puesta en práctica del método CLIL en nuestra Sección Bilingüe?, ¿con qué garantías contamos para que la introducción de las enseñanzas bilingües en determinados cursos de la ESO sea exitosa?, ¿cómo convencer a toda la Comunidad Educativa: profesores, padres y alumnos de que vamos en la buena dirección?. Estas son tan sólo algunas de las cuestiones que me surgieron antes de dar el paso definitivo. Para contestarlas busqué las respuestas en aquellos que cuentan con probada experiencia en este tema. Esta búsqueda dio sus resultados, pues de entrada la metodología CLIL ha venido aportando en situaciones diversas resultados positivos, hecho que es resaltado por J. Cummins, (1999, p. 2). Este investigador sostiene que "los programas bilingües aplicados con lenguas mayoritarias o minoritarias habladas por los estudiantes han contado con éxito en muchos países del mundo". De hecho del estudio realizado por J. Cummins y D. Corson, (1997) sobre esta cuestión se desprende que en los treinta países en los que los alumnos han sido educados en lengua que no es su L1 éstos no han sufrido consecuencias adversas en el desarrollo de sus habilidades académicas desarrolladas en su L1 sino todo lo contrario. Este éxito se debe en gran medida a que el modelo CLIL hunde sus raíces en la psicología cognitiva y en la importancia de desarrollar las competencias comunicativas del alumno. Estos fundamentos contribuyen a que el modelo CLIL esté plenamente integrado en la filosofía del Ilamado enfoque comunicativo del estudio de las lenguas.

Sin embargo, para lograr el pleno desarrollo de las competencias comunicativas de nuestros alumnos de enseñanza bilingüe a quienes se les aplica el método CLIL se hace preciso conocer primero los elementos que integran este método. Del primero de ellos ya hemos hablado al señalar el "baño natural" o la "inmersión lingüística" como la propuesta a seguir por el CLIL para lograr que el "aprendizaje" de la L2 se transforme, dentro de los posible en "adquisición". Nos referimos a un uso lo más natural de idioma extranjero por medio de la presentación al alumno de situaciones diarias en las que puede adquirir las competencias básicas en la L2 sin el esfuerzo supletorio que conlleva aprender los idiomas en las clases ordinarias destinadas al efecto. Y esta propuesta de aprendizaje natural toma cuerpo en el Ilamado "aprendizaje por tareas", según el cual el estudiante va asimilando la L2 por medio de la realización de pequeñas tareas que en principio no se relacionan con los elementos lingüísticos de dicho idioma. Como consecuencia de realizar un aprendizaje lo más natural y accesible al alumno, éste se siente más motivado para superar todos los retos que se le plantean en el dominio de la L2. De un modo gradual, así lo manifiesta Krahem (1999, p. 8) "la introducción de un programa bilingüe en las escuelas consigue que los alumnos aumenten su autoestima y logren comprender mejor los conceptos matemáticos que el profesor explica, al mismo tiempo que aumenta su nivel de competencia en L2". Y con un alumno motivado el éxito en el proceso de enseñanza y aprendizaje tiene muchas posibilidades de estar asegurado, pues no cabe duda de que si establecemos unas relaciones significativamente positivas entre la L1 y la L2 el estudiante contará con la habilidad para transferir de forma acertada conocimientos lingüísticos y académicos de la L1 a la L2 y viceversa sin mayor esfuerzo.

El segundo elemento al que tenemos que aludir son los recursos didácticos a utilizar en el modelo CLIL seleccionado. Nos referimos a unos materiales que deben resultar lo más 
auténticos posibles, es decir que puedan ser manipulados, transformados y completados por los alumnos en su uso en el aula y fuera de ella. Son recursos de fácil acceso y que están presentes en la vida diaria de nuestros estudiantes de la ESO: periódicos, revistas, canciones, folletos, videos musicales, DVDs, comics o poemas. Estos y otros nos sirven para poner en contacto al aprendiz con el uso más cotidiano y conversacional de la L2.

Pero todo este proceso no podría realizarse sin la colaboración imprescindible de un tercer elemento básico: el profesor. Aludimos a un profesional bien formado, cualificado e identificado con el método de enseñanza que aquí se propugna. Se trata de un docente capaz de gestionar con eficacia el tiempo que dedica a enseñar, de innovar e introducir elementos motivadores y estrategias interactivas en sus clases, al mismo tiempo que reflexiona sobre el modo de optimizar las relaciones entre la L1 y la L2. En definitiva se trata de una persona que en palabras de T. Naves y C. Muñoz, (2005, p. 15) que sea capaz de que "sus alumnos usen las lenguas extranjeras para aprender al mismo tiempo que aprenden a usar las lenguas extranjeras".

Aclarado el panorama ya nuestra decisión fue tomada a favor de introducir en nuestro IES una Sección Bilingüe. Y es dentro de la Programación Didáctica de dicha Sección donde se inserta la presente propuesta de Integración Curricular de la L1 y L2 cuyos pormenores pasamos a continuación a referir.

\section{Consideraciones preliminares}

A lo largo de los últimos cursos escolares se vienen sucediendo distintas iniciativas promovidas por las Administraciones Educativas españolas en pro de la introducción de la enseñanza bilingüe en los centros escolares. Una de ellas es la que se concreta en el Acuerdo del Consejo de Gobierno de la Junta de Andalucía de 22 de marzo de 2005, por el que se aprueba el Plan de Fomento del Plurilingüismo en Andalucía, (BOJA, no 65, de 5.4.2005). La filosofía que sustenta este Plan, promovido por la Consejería de Educación de Andalucía, se nutre de los principios lingüísticos, didácticos y pedagógicos que se definen en el Marco Común Europeo de Referencia de las Lenguas, (Consejo de Europa, 2001) y por ello el enfoque plurilingüe de la enseñanza que se intenta promover desde las Secciones Bilingües de los IES andaluces tiene como pretensión primaria poner en práctica el convencimiento de que a medida de que se expande la experiencia lingüística de un individuo en los entornos culturales de una lengua, desde el lenguaje familiar hasta el de la sociedad en general, y después hasta las lenguas de otros pueblos (ya sean aprendidas en la escuela o en la universidad, o por experiencia directa), dicho individuo no guarda estas lenguas y culturas en comportamientos mentales estrictamente separados, sino que desarrolla una competencia comunicativa a la que contribuyen todos sus conocimientos y experiencias lingüísticas y en la que las lenguas se relacionan entre sí e interactúan.

Pensando que la participación como Centro en alguno los Programas y Planes que integran el Plan Andaluz de Fomento del Plurilingüismo habría de resultar ventajoso para toda la Comunidad Educativa, un grupo de profesores/as del IES en el que trabajo, animados por los beneficios que podría reportar a nuestros alumnos la potenciación del desarrollo de sus competencia comunicativa en varias lenguas y de su capacidad para comprender mensajes y expresar contenidos curriculares y no curriculares diversos idiomas, nos decidimos a participar en la convocatoria para la selección de Centros Bilingües realizada 
por la Consejería de Educación en Orden de 6 de abril de 2005, (BOJA, ํo 66, de 6.4.05). Elaboramos y presentamos el correspondiente Proyecto Educativo y muy grata fue nuestra sorpresa al comprobar que dicho Proyecto fue oficialmente aprobado para su aplicación en nuestro Centro a partir del curso 2005/2006. En el primer curso de funcionamiento de nuestra Sección Bilingüe (español-inglés) y como Coordinador de la misma tuve que dedicar parte de mis esfuerzos a delimitar las líneas maestras de lo que a la que a la postre a de ser el CLIL, (Curriculum Integrado) o curriculo básico en el que se integren todas las áreas de la ESO que se impartan en la modalidad bilingüe. Y una de esas líneas consiste en la elaboración de una "Propuesta para la integración curricular de las Áreas de Lengua Castellana y Lengua Inglesa de la ESO para su aplicación en la enseñanza bilingüe". Tomando como punto de partida la definición de "competencia comunicativa" (Hymes, 1972) entendida como un "conjunto de estrategias y procedimientos creativos que le permiten al individuo entender y emplear los elementos lingüísticos utilizados en un contexto determinado, así como su capacidad de afrontar y regular una relación comunicativa, más allá de la mera competencia lingüística", este docente e investigador educativo elaboró la Propuesta que se presenta al lector en el presente artículo.

\section{Preámbulo de la propuesta}

La elaboración del "curriculum integrado de las lenguas" (CLIL) correspondiente a nuestra Sección Bilingüe se inscribe dentro de lo establecido en el Apartado 3.2.1, Programa: "Centros Bilingües", del Capítulo III del Plan Andaluz de Fomento del Plurilingüismo que viene recogido en el Acuerdo de 22 de marzo de 2005, del Consejo de Gobierno, por el que se aprueba dicho Plan, (BOJA, no 65, de 54.2005). Habiendo sido seleccionado el IES "Fernando Savater", (Código de Centro: 11001890) como Centro educativo que cuenta con Sección Bilingüe (inglés-español) a partir del curso 2005/2006,(Cfr. Resolución de 29.6.2005, de la Dirección Gral. de Ordenación y Evaluación Educativa, (BOJA, no 81, de 12.7.05) corresponde al Equipo Docente de dicha Sección la elaboración del CLIL para cada una de las áreas de enseñanza implicadas en el Proyecto Bilingüe y para todos los cursos de la ESO. Y todo ello en cumplimiento del compromiso adquirido por el Profesorado de la Sección Bilingüe al aceptar lo establecido en el art. 16 de la Orden de 6 de abril de 2005, (BOJA, no 66, de 6.4.2005).

Resultando que las finalidades educativas generales que se persiguen con la puesta en marcha de nuestra Sección Bilingüe son las siguientes:

a) Lograr que nuestros alumnos cuenten con el derecho a la adquisición de un nivel de competencia lingüística en la lengua materna y en el inglés que les permita su normal desenvolvimiento en todas las situaciones de comunicación.

b) Promocionar entre los alumnos la diversidad lingüística como un hecho cierto y constatable en la U.E., con el fin de que entiendan que todas las lenguas tienen el mismo valor en términos de medios de comunicación y de expresión de nuestra identidad.

c) Promover entre los alumnos la compresión mutua, dado que la comunicación intercultural y la aceptación de las diferentes culturas descansa sobre la mutua aceptación de los pueblos. 
d) Fomentar entre el alumnado la idea de una ciudadanía democrática que reconozca y respete las diferencias y aspire a la igualdad de trato entre los ciudadanos de los distintos países de la U.E.

e) Propiciar entre los alumnos la cohesión social, ya que la igualdad de oportunidades en el desarrollo personal, educativo, profesional, de acceso a la información y de enriquecimiento cultural depende de la posibilidad real de aprender lenguas a lo largo de toda la vida.

Parece claro que las enseñanza regladas de la ESO, acogidas a la modalidad de "enseñanza bilingüe", deben estar presididas, al menos por los siguientes criterios:

\section{A. En cuanto al modelo de enseñanza-aprendizaje}

El Profesorado de la Sección Bilingüe está comprometido con la promoción de un modelo de enseñanza bilingüe, en el cual lo importante es que los alumnos asimilen determinadas parcelas de conocimiento de algunas áreas de la ESO contado con el inglés como lengua instrumental. Ello sin olvidar que el español, como lengua materna, es lengua de aprendizaje que debe servir de base para el desarrollo de todos los contenidos escolares.

El método de enseñanza bilingüe se define como " método natural de baño de lengua", es decir un método de inmersión lingüística por medio del cual los alumnos de la ESO deben estar el mayor tiempo posible expuestos al contacto oral y escrito con el inglés.

\section{B. En cuanto al punto de vista lingüístico}

Nuestro modelo de enseñanza bilingüe pretende lograr que los alumnos mejoren sus competencias lingüísticas tanto en inglés como en español. Lo verdaderamente importante es desarrollar en el alumno una verdadera conciencia lingüística confrontando códigos diferentes que le induzcan a reflexionar sobre el comportamiento de las lenguas. $\mathrm{Y}$ a ello tienen que llegar básicamente con la ayuda del Profesor de lenguas, tanto materna como extranjera, pero también con la intervención del Profesorado de otras áreas que imparten sus materias esencialmente en lengua inglesa.

Este movimiento de una lengua a otra tiene que incrementar la competencia metalingüística de los alumnos, desarrollar una conciencia lingüística que permita al estudiante distanciarse y comprender con claridad las formas lingüísticas que emplea en su Centro de estudio. A tal fin hemos de propiciar el desarrollo en los alumnos de la competencia mediadora,(De Arriba, 2003) como una subcompetencia de la competencia comunicativa, a saber: la capacidad del alumno para desenvolverse en su lengua materna (L1) o en otras lenguas (L2) y establecer contacto con los demás individuos, en definitiva se trata de que los estudiantes desarrollen sus microhabilidades orales y textuales para poner en práctica la mediación lingüística. El desarrollo de la competencia mediadora en los alumnos es tan esencial como el resto de competencias en L2, las cuales son, según Van Ek: competencia lingüística, competencia sociolingüística, competencia discursiva, competencia estratégica, competencia sociocultural y competencia social. Ello sin olvidarnos de la competencia traductora (v. Wilss, 1977); Höning Kussmaul, 1982; Toury, 1980; Harris y Sherwood, 1978; Hurtado, 2001, entre otros) que sin alcanzar niveles de ejercicio profesional ha de estar presente en los alumnos de la ESO y Bachillerato. 


\section{En cuanto al punto de vista cultural}

El trabajo de nuestra Sección Bilingüe está encaminado a que nuestros alumnos entren en contacto desde $1^{\circ}$ de ESO con otras realidades culturales para que puedan establecer pronto comparaciones. Con ello pretendemos despertar su interés y curiosidad por otras culturas, costumbres, instituciones y técnicas. Esta apertura de mente es el camino esencial para fomentar la libertad, la tolerancia, la solidaridad, el respeto al pluralismo como valores esenciales de la educación. Con ello lograremos que afronten del modo más adecuado su incorporación a la ciudadanía europea, gracias a la cual deben disfrutar de una sociedad plural, democrática y moderna, libre de prejuicios y estereotipos.

\section{En cuanto al punto de vista cognitivo}

El modelo de enseñanza que se imparte en nuestra Sección Bilingüe pretende que el dominio del uso de los idiomas acreciente las capacidades generales de aprendizaje de los alumnos. En nuestras clases intentamos que los estudiantes confronten varios códigos lingüísticos desarrollando una gran flexibilidad cognitiva, la cual favorezca su observación y análisis de las operaciones utilizadas en los propios procesos de aprendizaje.

La práctica de la enseñanza bilingüe tiene que ayudar al alumno a reflexionar sobre el funcionamiento lingüístico y comunicativo de las lenguas, gracias a lo cual ha de regular el aprendizaje de ellas y ha de mejorar sus producciones lingüísticas.

La puesta en práctica de estos criterios pedagógicos demanda de nuestra Sección Bilingüe el desarrollo y la implantación de un nuevo modelo curricular. La finalidad última de este modelo ha de ser proporcionar al conjunto de la Comunidad Escolar un curriculo integrado de las lenguas y de las áreas no lingüísticas que pueda homologarse al usado por otros países de la U.E. En tal sentido, nuestro CLIL ha de posibilitar una educación lingüística global que haga hincapié en el desarrollo de la lengua materna del alumno, sin menoscabo de la práctica de otras lenguas.

A ello hemos de añadir que nuestro CLIL tiene en cuenta el principio fundamental de que la anticipación del aprendizaje de las lenguas extranjeras a edades tempranas es el mejor recurso para propiciar que los alumnos que desde E. Primaria llegan a la ESO puedan recibir una enseñanza bilingüe de verdadera calidad. Un aprendizaje temprano que, en nuestro caso, ya es una realidad en el alumnado de E. Infantil y Primaria del CP "Blas Infante", Centro hermanado en la experiencia bilingüe con nuestro IES.

Sin embargo, el hecho de que nuestra Sección Bilingüe atienda ahora a alumnos de la ESO, y en un próximo futuro a alumnos de Bachillerato, requiere que nuestro CLIL traspase las barreras de las Programaciones Didácticas de cada Dpto. implicado y de lugar a un nuevo modelo curricular cuya seña de identidad sea una enseñanza bilingüe que fomente la apertura de nuestro Centro a la sociedad, que desarrolle actividades extraescolares con otros Centros y que dinamice los intercambios del Profesorado y alumnado con otros Centros de la U.E.

La elaboración de nuestro CLIL tiene que aunar las áreas lingüísticas y no lingüísticas bajo la misma filosofía, a saber: contemplar las capacidades del alumno en relación con la reflexión sobre las lenguas, en relación con su familiarización con las culturas que las lenguas vehicúlan y en relación con el empleo de la lengua materna y la no materna en 
la adquisición de los contenidos objeto de estudio. En este sentido el CLIL contempla la elección de contenidos de las diferentes materias y, en su concreción, favorece el desarrollo de la dimensión europea de la educación, fomenta el trabajo cooperativo sobre los fenómenos culturales y científicos de los países de nuestro entorno.

No obstante, poco valor tendría la elaboración del CLIL si el Profesorado implicado en nuestra Sección Bilingüe no se diera cuenta que esta modalidad de enseñanza no consiste en una mera traducción al inglés de los contenidos impartidos en las diferentes áreas, ya que de lo que se trata es de que los alumnos piensen en inglés, sientan y vivan sus experiencias en el aula en inglés. Se trata de que cada docente cuente con una amplia batería de recursos educativos para enseñar "en inglés", olvidando las traducciones y las comparaciones con la lengua materna.

Conscientes de que la enseñanza bilingüe aspira a lograr el perfeccionamiento lingüístico de nuestros alumnos, todos nuestros esfuerzos han de centrarse en lograr una sensible mejora de sus niveles de comunicación oral y por lograr que aumente el dominio del léxico en inglés correspondiente a las áreas no lingüísticas. Al margen de ello, nuestro CLIL pretende configurar unidades temáticas de contenidos y con ello dar coherencia a los distintos aprendizajes que incluyen estrategias interdisciplinares yuxtapuestas y reunidas en diferentes actividades de aprendizaje. De ello se desprende que el Profesorado de las áreas no lingüísticas tiene que adecuar los niveles de aprendizaje de los alumnos en función de la lengua empleada en cada momento de la clase y en relación con los contenidos de la materia. A tal fin, el material no verbal ha de ser empleado desde el principio: dibujos, esquemas, croquis, gráficos, estadísticas, caricaturas, etc. Al comienzo el léxico ha de presentar escasas dificultades para ir en posteriores etapas afinando el dominio del vocabulario, lo cual redundará en un mejor conocimiento de la lengua y la cultura inglesa.

Al elaborar este CLIL nos damos cuenta de que nuestro nuevo modelo curricular aportará coherencia metodológica al proceso de enseñanza-aprendizaje, eliminará reduplicaciones y redundancias y permitirá el refuerzo entre las diferentes materias. Por ello, mediante las reuniones del Equipo Docente de la Sección Bilingüe se ha de coordinar el trabajo realizado por todos los Profesores a fin de que caminemos en la misma dirección a la hora de enseñar determinados contenidos por medio del inglés, al mismo tiempo que equiparamos nuestros niveles de exigencia en cuanto a las competencias lingüísticas que deben alcanzar los alumnos en cada área objeto de estudio en la ESO. El trabajo bien coordinado de nuestro Equipo Docente permitirá elaborar proyectos pluriculturales y multiculturales, dando al mismo tiempo lugar a la incorporación de un estudio comparativo lingüístico, a la anticipación de determinados contenidos gramaticales y al avance en técnicas y procedimientos a trabajar por el alumno en las diversas áreas.

Establecidas estas premisas fundamentales que han de presidir la elaboración del CLIL de cada una de las áreas de la ESO implicadas en el Proyecto Bilingüe, pasamos a determinar el marco normativo, metodológico, curricular y pedagógico sobre el que se ha de sustentar la integración del "curriculum" de las áreas de Lengua Castellana e Inglés. Entendemos desde un principio que no se trata de impartir los contenidos del área de Lengua Castellana y Literatura de la ESO en inglés, sino que el esfuerzo ha de enfocarse en la búsqueda de estrategias que hagan que el alumno pueda usar de forma indistinta ambas lenguas para expresar sus pensamientos, sentimientos, deseos o deman- 
das. En definitiva, se trata de crear en los adolescentes una mentalidad bilingüe, de tal modo que de forma espontánea tanto los contenidos conceptuales, procedimentales y actitudinales como las propuestas de actividades puedan formularse y resolverse en ambas lenguas. A la postre de lo que se trata es que el alumno domine de forma indistinta ambas lenguas y las use en las mismas situaciones de comunicación.

Siguiendo estos principios nos disponemos a elaborar la presente propuesta de CLIL partiendo de los principios normativos que sobre el curriculo de la ESO se establecen, tanto a nivel del Estado en el Real Decreto 83/2003, de 27 de junio, (BOE, no 158, de 3.7.2003) como de la C.A. Andaluza, en el Decreto 148/2002, de 14 de mayo, (BOJA, $\mathrm{n}^{\circ}$ 75, de 27.6.2002) ${ }^{[1]}$, añadiendo a ello las orientaciones establecidas en el Marco Común Europeo de Referencia de las Lenguas y el Portfolio de las Lenguas Europeas. De acuerdo con los objetivos, contenidos y metodología que se exponen en dicho MERL para efectuar una enseñanza bilingüe en la E. Secundaria, resulta claro que en el caso del CLIL de Lengua Castellana y Literatura e Inglés hemos de partir del concepto básico de "Literacy". And what is literacy?:

"Literacy is much more than just teaching of the mechanics of reading. Literacy encompasses the four skills of languaje: understanding, speaking, reading and writing. An integration of this skills provides the pupils with a grater chance of survival in English and encourages self-esteem, self-identity and emotional development."

Es decir, se trata de enseñar cualquiera de las áreas de la ESO, en este caso la de Lengua Castellana y Literatura a través del inglés, usando los mismos resortes pedagógicos y las mismas estrategias que cualquier Profesor inglés que imparta estas materias en su país. Integrar el curriculum de ambas materias en un sólo implica que el Profesor debe ayudar a los alumnos a expresarse, escribir, conversar y relacionarse usando el inglés como una lengua instrumental para trabajar cualquiera de los contenidos del área de Lengua Castellana y Literatura en los cuatro cursos de la ESO.

But, how should Literacy be developed whitin a whole-school context? Esto será posible, if the students being able to to read and communicate with fluency and enjoyment in English. To develop these in Secondary, is necesary for teachers to:

a) Always address the students in English.

b) Ensure a bilingual enviroment, (posters, signs, etc,).

c) Coordinate between departments, sharing key vocabulary and concepts.

d) Try to promote "bilingual events", e.g. book week, St Patric's day, Shakespeare and Cervantes' day, etc.

[1] Hay que tener en cuenta que esta Propuesta de Integración curricular se hizo antes de la aprobación de la LOE, hecho que en modo alguno limita su plena actualidad, toda vez que en los RRDD de desarrollo de la LOE y el los DD de aplicación de la LOE en la C.A. Andaluza se mantienen las mismas orientaciones pedagógicas sobre la enseñanza bilingüe. De todos modos actualizamos las citas de normativa educativa, que a nivel de Estado sería el Real Decreto 1631/2006, de 29 de diciembre, por el que se establece el curriculo básico de la ESO, y a nivel autonómico el Decreto 231/2007, de 31 de julio, por el que se establece la ordenación y las enseñanzas correspondientes a la ESO en Andalucía. 
Partiendo de esta necesidad de envolver nuestra práctica docente en el modo de pensar y de expresarse propio del hablante inglés estamos en disposición de impartir una verdadera enseñanza bilingüe.

\section{Hacia un enfoque competencial de los objetivos, contenidos y criterios de evaluación}

Nuestra propuesta de Integración Curricular no puede ser elaborada sin tener en cuenta ni las directrices básicas que se establecen en los curriculos oficiales de las áreas en cuestión, ni la finalidad primaria que en ellos se determina en relación con la enseñanza de las lenguas; a saber: que las competencias comunicativas que el alumno de la ESO debe alcanzar y el desarrollo de su comprensión oral y escrita son el motor de su formación personal, de su autonomía para adquirir conocimientos futuros y de su desarrollo integral como persona. De aquí se desprende que la Integración Curricular de las áreas citadas debe contribuir a desarrollar en los estudiantes cuatro habilidades lingüísticas básicas: escuchar, hablar, leer y escribir, así como propiciar su tránsito desde el uso funcional de la lengua a la reflexión sistemática sobre la misma.

Desde esta óptica del desarrollo competencial en habilidades comunicativas tanto los objetivos como los contenidos de nuestra propuesta han de tener elementos comunes. Esto supone que si desde el área de Lengua Castellana y Literatura pretendemos que el alumno adquiera un conjunto de conocimientos sobre la lengua y de procedimientos de uso de la misma que le son necesarios para interactuar en diferentes ámbitos sociales, no ha de ser muy diferente lo que se pretenda desde el área de Lengua Inglesa. Por ello, con el desarrollo del curriculo de esta área se pretende que el estudiante adquiera las destrezas discursivas que le faciliten el acceso a una actividad comunicativa en la que se requiera el uso de la L2 en su expresión oral y escrita. Actividad comunicativa en la que debe ser capaz de utilizar recursos y estrategias de comunicación lingüística y no lingüística dentro del contexto en el que el hecho comunicativo se produce.

Sin embargo, el enfoque competencial y comunicativo que se desprende de los curriculos oficiales de la L1 y la L2 nos ayuda aún más en nuestro intento por delimitar los objetivos y contenidos de nuestra propuesta integradora. En dichos curriculos se subraya el hecho del que el alumno de la ESO debe ser capaz de escuchar, hablar, leer y escribir tanto para desenvolverse con soltura en la interacción social como para lograr la adquisición de nuevos conocimientos. Ello significa que desde los curriculos oficiales de ambas lenguas se están abriendo las puertas al uso de la L2 para el aprendizaje de los contenidos de las áreas no lingüísticas; es decir, justo lo que se pretende con el modelo CLIL de enseñanza bilingüe. En esta presentación de los propósitos comunes que desde el curriculo oficial se asignan a la L1 y L2 se sustenta nuestra ejemplificación, pues en ella se manifiesta que el alumno que a lo largo de la ESO estudie el inglés como L2 tendrá que ser capaz de enfrentarse de forma gradual y flexible a los mismos problemas cotidianos de comunicación oral y escrita que ahora es capaz de resolver en su lengua materna, tendrá que ser capaz de participar en conversaciones habituales, plantear quejas, relatar experiencias, explicar conceptos o pedir colaboraciones. Hablamos de un dominio de la L2 que se fundamenta en el desarrollo de las habilidades lingüisticas productivas: hablar, conversar y escribir en inglés; así como de las receptivas: escuchar, comprender, leer y componer. 
Tomando como base estas consideraciones se delimitan los objetivos generales que se pretenden con la presente propuesta de Integración Curricular:

\subsection{Consideraciones preliminares}

El primer nivel de concreción de nuestro CLIL pasa por delimitar los objetivos pedagógicos primarios que de pretenden lograr con la aplicación en el aula de dicho curriculo. En la delimitación de estos objetivos partimos del hecho incontestable de que la lengua, cualquier lengua, es un instrumento de comunicación y de acción sobre nuestro mundo, a la par que es un instrumento básico de interacción social. Por ello la enseñanza de toda lengua ha de tener como objetivo básico el formar personas competentes en el uso de los idiomas, usuarios que utilicen dichas lenguas en distintas situaciones y con finalidades diversas, al mismo tiempo que las emplean con adecuación, sentido y coherencia para cada acto del habla, es decir: un uso reflexivo e inteligente de las lenguas.

De acuerdo con esta premisa, las lenguas tienen que estar presentes en todas las áreas de aprendizaje de la ESO como un sistema de comunicación, como un medio de aprendizaje y como un sujeto de aprendizaje. Es por ello que podemos destacar la importancia de la intervención de las lenguas en los procesos de aprendizaje, las usamos para denominar los objetos que nos rodean, para relacionarnos con los demás, para la propia reflexión, etc. Todas estas actividades humanas descansan, en gran parte, en nuestro dominio de los recursos lingüísticos.

Al mismo tiempo, no podemos olvidar que la lengua de un determinado grupo humano es una parte inestimable del patrimonio histórico y cultural del dicho grupo que se desarrolla como instrumento de comunicación interna, y por tanto de cohesión social. Es por ello que la lengua se convierte en un signo de identidad y como un vehículo de manifestación artística propio de cada etnia. Este concepto de lengua y de lenguaje subyace en nuestro CLIL, y dado que dicho "curriculo integrado" para las áreas de Lengua Castellana y Literatura e Inglés en la ESO ha de tener un enfoque integrador de la enseñanza de ambas lenguas, parece adecuado que redactemos una propuesta curricular única que se refiera al desarrollo de las capacidades comunicativas de los alumnos en las dos lenguas. Este enfoque integrador es el resultado de la convergencia de los objetivos, de la elaboración de planteamientos didácticos similares, de contar con ámbitos de reflexión comunes, así como pretende evitar repeticiones innecesarias de contenidos y ofrecer una misma terminología en todos los casos.

La necesidad de este planteamiento integrador viene justificada por la existencia de un mismo sujeto de aprendizaje y por la conveniencia de realizar la transferencia de aprendizajes lingüísticos realizados en diferentes lenguas, especialmente de aqueIlos relacionados con la competencia comunicativa del alumno. Una transferencia que posibilite una práctica enriquecedora de la competencia plurilingüe que la sociedad actual requiere. En función de ello, el enfoque integrador del CLIL ha de favorecer la planificación conjunta de las materias objeto de estudio en la ESO, lo que supone que el Profesorado de la Sección Bilingüe ha de tomar decisiones conjuntas sobre aquellas cuestiones que permitan asegurar una buena coordinación de los Pro- 
gramas escolares y de las actividades didácticas, así como una buena transferencia de aprendizajes al alumno.

Otro de los pilares en los que se sustenta nuestra delimitación de estos objetivos generales es nuestro concepto de lengua y cómo usarla. Esta concepción hunde sus raíces en el enfoque comunicativo y funcional de la lengua, el cual se caracteriza por trabajar con el alumno las habilidades lingüísticas de una manera integrada, siempre partiendo de las necesidades comunicativas y de las diversidad discursiva del estudiante en situaciones reales del aula. En consecuencia con este concepto de lengua, en nuestras clases insistimos sobre el uso de las lenguas como medio para desarrollar las habilidades y las competencias comunicativas del alumno. Con ello lograremos que la lengua configure su pensamiento, le sirva para la conceptualización de sus experiencias y como punto de partida para el uso de la lengua escrita. Por un lado, el dominio del español y del inglés ha de mover al alumno a desarrollar sus capacidades comunicativas y a descubrir las posibilidades que nos ofrecen la lectura y la escritura como fuentes de placer y de fantasía. Mientras que, por otro, la enseñanza de las lenguas ha de tender a desarrollar el conocimiento del hecho literario como un producto cultural y social en la sociedad del siglo XXI.

\subsection{Delimitación de los objetivos}

La enseñanza integrada de la Lengua Castellana y Literatura, y la Lengua Inglesa que pretendemos aplicar en nuestro CLIL persigue los siguientes objetivos para la ESO:

1. Comprender discursos orales y escritos e interpretarlos con una actitud crítica, reconociendo las diferentes finalidades y las situaciones de comunicación en que se producen.

2. Comprender y producir con corrección diversos tipos de mensajes en español e inglés, tanto orales como escritos, aplicando las técnicas del análisis y síntesis.

3. Alcanzar un alto nivel de competencia lectora en inglés y español y desarrollar una actitud crítica hacia los textos escritos, valorando la lectura y la escritura como formas de comunicación que constituyen fuentes de enriquecimiento cultural y de placer personal.

4. Reflexionar sobre los elementos formales y los mecanismos de construcción y uso de las dos lenguas en los niveles fonológico, ortográfico, morfológico, morfosintáctico, léxico, semántico y textual, así como valorar las condiciones de producción y recepción de cada una de las lenguas, con el fin de desarrollar la capacidad de regular las propias producciones lingüísticas.

5. Acceder con autonomía creciente a las obras literarias en español e inglés como forma destacada del patrimonio cultural de los pueblos español e inglés.

6. Reconocer los principales géneros y formas de tradición literaria española e inglesa, así como las principales corrientes, autores y obras.

7. Apreciar la riqueza que supone el dominio de ambas lenguas y culturas como formas distintas de codificar la experiencia y de organizar las relaciones interpersonales. 
8. Conocer y valorar la realidad plurilingüe de Europa y de la sociedad en la que vivimos, aceptando las distintas lenguas como signo de riqueza y superando los estereotipos sociolingüísticos, así como asimilando los problemas que platean las lenguas en contacto.

9. Reconocer y analizar los elementos y las características de los medios de comunicación y valorar su importancia en las manifestaciones culturales contemporáneas, ello con el objeto de ampliar las destrezas discursivas tanto en español como en inglés, al mismo tiempo que se desarrollan las actitudes críticas en relación con los mensajes que los medios nos transmiten.

10. Utilizar el español y el inglés como instrumentos para nuevos aprendizajes, para la comprensión y análisis de la realidad y para el desarrollo del pensamiento, así como para la regulación de la propia actividad, facilitando con ello el manejo de las técnicas de la información y de las tecnologías de la comunicación.

\section{Propuesta de contenidos}

Nuestra pretensión de ofrecer una propuesta de contenidos que facilite la integración curriculum de la L1 y L2 en el modelo de enseñanza bilingüe pasa por admitir que en ambas lenguas hablamos de bloques de contenidos que se vinculan con las habilidades y estrategias que el alumno ha de desarrollar para hablar, escribir, escuchar y leer en los ámbitos significativos de la vida escolar. Estos bloque se concretan en la L1 del modo siguiente:

$1^{\circ}$. hablar, escuchar, conversar.

$2^{\circ}$. leer y escribir.

$3^{\circ}$. educación literaria.

$4^{\circ}$. conocimiento reflexivo de la lengua.

En el caso de la L2, dichos bloques quedan del siguiente modo:

$1^{\circ}$. hablar, escuchar, conversar.

$2^{\circ}$. leer y escribir.

$3^{\circ}$. conocimiento de la lengua.

$4^{\circ}$. aspectos socioculturales y conciencia de interculturalidad.

Resulta notorio precisar que en los dos casos los contenidos se presentan agrupados en bloques en función de tres ejes esenciales en los que se concentran las características y necesidades específicas en el proceso de enseñanza-aprendizaje de las lenguas:

a) el dominio de las habilidades lingüísticas.

b) el conocimiento de los elementos constituyentes de los sistemas lingüísticos, su funcionamiento y relación.

c) el estudio de las dimensiones socioculturales de la L2.

A partir de esta delimitación de las líneas maestras se hace preciso especificar cómo estas se concretan en los bloques de contenidos para cada una de las lenguas objeto de la presente propuesta de integración. Tanto para la L1 como para la L2 las habilidades 
lingüísticas se establecen en los Bloques $1^{\circ}$ y $2^{\circ}$ : escuchar, hablar, conversar, leer y escribir. Y para ambas lenguas se establece una gradación del aprendizaje de los contenidos propios de estos dos Bloques, la cual se basa en criterios de mayor o menor proximidad del alumnos a las prácticas discursivas, del grado de complejidad de los textos trabajados en cuanto a su organización interna y de la diversificación de los fines que se asignan a la interpretación y composición de los textos orales y escritos.

Por lo que respecta al Bloque dedicado al uso reflexivo y al conocimiento de la lengua podemos observar que en ambas lenguas existen elementos comunes que refuerzan nuestra propuesta de integración curricular en el marco de la enseñanza bilingüe. De entrada en ambos casos se pone de relieve que conocer una lengua significa adquirir las habilidades lingüísticas y comunicativas adecuadas para usarla correctamente, lo que implica hacer un uso reflexivo de la L1 y de la L2. En un segundo lugar se insiste en la necesidad de conocer las lenguas que se usan, tanto la materna como la L2. Y conocer la lengua inglesa en profundidad implica crear en el aula situaciones de uso que favorezcan en el alumno la inferencia de sus reglas de funcionamiento a partir de los elementos comunes que comparte con su propia lengua,

Por su parte, en el Bloque $4^{\circ}$ se destacan los aspectos socioculturales y la conciencia de interculturalidad que hay que despertar en los alumnos de la ESO por medio del estudio de la L2. Aquí se subraya que el hecho de conocer un nuevo idioma implica conocer nuevas costumbres, formas distintas de relación social, así como los rasgos y peculiaridades propios de los hablantes nativos de esa lengua.

Teniendo presentes estas consideraciones se realiza la siguiente propuesta de contenidos:

\section{A. Bloque 10: La comunicación interpersonal. Uso y formas de la comunicación oral y escrita}

A.1. Contenidos conceptuales

\begin{tabular}{ll}
\hline Lengua y Lta. Española & Puntos de contacto con el Inglés \\
\hline $1^{\circ}$ de ESO &
\end{tabular}

1. La comunicación: elementos.

2. Tipos de textos orales y escritos: textos espontáneos y planificados.
1. Funciones del lenguaje: saludar, despedir, comprender información.

2. Fórmulas y saludos: to be/have got.

3. Dar, pedir, comprender instrucciones y direcciones: How can I get to the Post Office?

4. Describir y comprender personas, lugares, situaciones, y conversar dando y pidiendo información: Next to, behind, opposite, etc. 


\section{Lengua y Lta. Española} $2^{\circ}$ de ESO

1. La comunicación: funciones.

2. Tipos de textos orales y escritos: textos espontáneos y planificados.
Puntos de contacto con el Inglés

1. Expresión de hábitos, gustos, habilidades, conocimientos, estados de ánimo, etc. Pte.simple con adverbios de frecuencia: always, often, usually, etc.

Love/like, don't like/hate + sustantivo.

2. Dar, pedir, comprender información sobre acciones pasadas o en transcurso: Pte.continuo/Pte.simple: now, today, Monday, etc.

\section{$3^{\circ}$ de ESO}

1. La comunicación: procedimientos de modalización.

2. La comunicación oral: peculiaridades y tipos.

3. La comunicación escrita: ídem.

4. Tipos de texto según estructura secuencial dominante.
1. Funciones del lenguaje: saludos, la presentación formal. Pedir información, dar información personal. Pte. simple y adverbios de frecuencia:

Nice to meet you What's your address?

2. Preguntas/respuestas sobre hechos del pasado o no han terminado aún. Pte.perfecto y pasado simple: Ever/never, just/when.

3. Hacer sugerencias y responder a las mismas: How, what about + ing forms

\section{$4^{\circ}$ de ESO}

1. La comunicación oral: técnicas.

1. Describir y comparar hábitos y estilos

2. La comunicación escrita: técnicas.

3. La comunicación no verbal.

4. Tipología textual según estructura secuencial dominante. de vida. Expresar gustos y preferencias. Uso de Pte.simple y continuo: used to + infinitivo.

2. Expresión de hechos pasados vinculados con el presente. Pte. o pasado continuo: for, since, already, jet, etc. 


\section{A.2. Contenidos procedimentales}

\section{Para el Área de Lengua y Lta. Española Puntos de contacto con el Inglés}

1. Reconocimiento de los elementos de la comunicación en textos orales y escritos en una situación comunicativa concreta:

a) Reconocimiento de los interlocutores que aparecen en un texto y de las relaciones que se establecen a nivel formal.

b) Reconocimiento de los principales elementos modalizadores de un texto oral y escrito.

c) Determinación de las funciones comunicativas presentes en un texto mediante el análisis de las marcas características.

2. Compresión y producción de textos orales:
a) Compresión y clasificación de mensajes orales de todo tipo.
b) Identificación del tema de un texto: ideas principales y secundarias.
c) Preparación y producción de textos orales espontáneos y planificados.
d) Lectura expresiva en voz alta.
e) Dramatización.
f) Memorización
g) Análisis y aplicación de las normas de intercambio comunicativo oral.
h) Resumen oral de textos.
i) Manejo de los MAVs para la elaboración de mensajes orales.
k) Análisis y uso de la lengua de acuerdo al registro requerido en cada situación comunicativa.

1. Funtional English: it is expected that our pupils will have a repertoire of classroom phrases. These need to be practiced and developed so that the pupils can funtion in other subject areas.

2. To understand and respond to others, pupils will be able to:
a) Sustain their attention.
b) Listen individually and in groups to the teacher giving detailed explanations, presentations and telling stories.

3. Listen to recordings and other in groups.

4. Writing: students should practice modelling their writing from given texts and using frames e.g. sentences starters, linking words, story sequencers...

5. Writing Composition:

a) Map out texts showing development and structure, e.g. its high points, the links between sections, paragrahs, chapters.

b) Use different ways of plannig stories: e.g. brainstorming, notes and diagrams. 
Para el Área de Lengua y Lta. Española Puntos de contacto con el Inglés

3. Compresión y producción de textos escritos:

a) Comprensión y clasificación mensajes escritos de todo tipo.

b) Identificación de la intencionalidad y reconocimiento del contenido ideológico de textos escritos.

c) Reconocimiento de hechos, opiniones e interpretaciones en un texto escrito.

d) Identificación del tema de un texto: ideas principales y secundarias.

e) Reconocimiento de las peculiaridades formales de los textos escritos.

f) Producción y revisión de los textos escritos.

g) Utilización de textos escritos con finalidades diversas.

h) Conversación sobre textos orales y escritos.

i) Resumen de textos escritos.

j) Transformación de textos de un registro a otro.

k) Análisis del uso de la lengua de acuerdo al registro requerido en cada situación comunicativa.

A.3. Contenidos actitudinales

1. Valoración de las lenguas como instrumentos para satisfacer una amplia gama de necesidades de comunicación.

2. Valoración positiva de las normas que regulan los intercambios comunicativos.

3. Valoración de la lengua oral y escrita como una forma de conocimiento, placer, persuasión, información, manipulación, etc.

4. Respetar las convenciones que regulan la lengua oral y escrita.

5. Interés, esfuerzo y autoexigencia en la elaboración rigurosa y sistemática de las producciones propias, reconociendo el error como parte integrante del aprendizaje.

6. Respeto hacia las opiniones ajenas expresar en lengua oral y escrita. 
7. Valoración del esfuerzo de los demás por mejorar la expresión oral y escrita.

8. Valoración de las modalidades de la lengua estándar oral.

\section{B. Bloque $2^{\circ}$ : El texto y las referencia lingüísticas}

\section{B.1. Contenidos conceptuales}

\begin{tabular}{ll}
\hline Lengua y Lta. Española & Puntos de contacto con el Inglés \\
\hline $1^{\circ}$ de ESO &
\end{tabular}

1. La norma fonética y ortográfica.

2. La Gramática:
a) El sustantivo: morfología.
b) La oración simple.

3. Léxico: la estructura del sustantivo.
1. Pronunciación de fonemas y morfemas de plural y de pasado simple de verbos regulares, defectivos y débiles: must/mustn't.

2. Pronunciación de las formas fuertes y débiles de las funcionales más importantes: was/were/can/some, etc.

3. Acentuación de palabras y frases, la entonación de la frase: wh-, yes/no, etc.

4. Desarrollar el léxico propio de la familia amigos, animales, alimentos, tiempo, ropa lugares, vacaciones, etc.

\section{2o de ESO}

1. La norma fonética y ortográfica: sonidos y grafías de la lengua.

2. La Gramática:
a) Sintagmas, complementos, relacionantes.
b) La oración simple: clases.

3. Léxico: relación entre sustantivos por forma y significado.
1. Pronunciación de fonemas de especial dificultad, tanto vocálicos como consonánticos: schwa,/w/versus/i:/

2. Pronunciación de formas contractas: will('Il), will not (won't)/could not/couldn't.

3. Uso de léxico relacionado con: el ocio, tiempo libre, asignaturas, objetos de uso diario, etc. 
Lengua y Lta. Española $3^{\text {o }}$ de ESO

1. La norma fonética y ortográfica: las interferencias fonéticas.

2. La Gramática:
a) Categorías y funciones.
b) La oración compuesta.

3. Léxico: mecanismos de formación de palabras.

4. Las interferencias léxicas.

5. El texto:
a) El texto según los registros lingüísticos.
b) La presentación oral y escrita de los textos.
c) La variación estilística.

\section{Puntos de contacto con el Inglés}

1. El léxico de las relaciones personales y sociales.

2. Expresión de la obligación y la ausencia de la misma: Have to/don`t? have to/must/mustn`t?/ should.

\section{4 de ESO}

1. La norma fonética y ortográfica: uso ortográficos correctos.

2. Gramática: texto y discurso.

3. Léxico: formación léxica de la lengua.

4. Interferencias morfológicas y sintácticas.

5. El texto: características:
a) Coherencia.
b) Cohesión.

1. Expresión de preferencias/opiniones. Aceptar y rechazar invitaciones: I like/ enjoy/hate + verbo-ing.

2. Expresiones de procesos y cambios: voz pasiva. 


\section{B.2. Contenidos procedimentales}

\section{Para el Área de Lengua y Lta. Española Puntos de contacto con el Inglés}

1. Identificación y aplicación de normas ortográficas y morfológicas en la producción de textos.

2. Reconocimiento y clasificación de las unidades lingüísticas de los textos.

3. Manejo de los diferentes tipos diccionario.

4. Utilización de mecanismos de formación de palabras.

5. Precisión y variedad en el uso del léxico en las producciones propias.

6. Reconocimiento y corrección de las interferencias fonéticas, léxicas, morfológicas y sintácticas.

7. Reconocimiento de las relaciones entre situación, contexto y registro de uso.

8. Reconocimiento e identificación de las marcas de adecuación del texto al contexto.

9. Identificación de la estructura informativa de los textos.

10. Reconocimiento y uso de procedimientos de cohesión textual.

11. Corrección de textos orales y escritos.

12. Utilización de las convenciones de la presentación oral y escrita.

13. Transformación de textos, secuencias y oraciones por procedimientos de substitución, ampliación y reducción.

14. Análisis, planificación y producción de diferentes tipos de textos según la estructura secuencial dominante.
1. Grammatical awereness:

a) To disccus, proof and edit their own writing for clarity and correctness.

b) To be aware that their own writing can be adapted for different readers and purposes by changing vocabulary, tone and sentence structures to suit; e.g. rewriting as a newspaper article and diary entry.

2. Rivise and extend the work on verbs tenses froms primary focus on:

a) Tenses: past, present, present perfect and future.

b) Forms: active, interrogative, imperative.

c) Person. 1aㅡ, $2^{\mathrm{a}}, 3^{\mathrm{a}}$, identify and classify examples from reading.

\section{B.3. Contenidos actitudinales}

1. Valoración de la importancia de la reflexión lingüística para regular la producción en lengua propia y extranjera.

2. Valorar la planificación textual y la revisión de los textos de acuerdo con los criterios de adecuación, cohesión, coherencia y corrección. 
3. Valoración de la precisión semántica en el uso de las lenguas.

4. Respeto por las convenciones lingüísticas y por las normas de corrección, coherencia, cohesión y adecuación.

5. Interés y esfuerzo en la elaboración de las producciones propias.

6. Sensibilidad crítica ante la incoherencia textual propia y ajena.

\section{Bloque $3^{o}:$ La comunicación literaria}

\section{C.1. Contenidos conceptuales}

\section{Lengua y Lta. Española} 1을 ESO

1. La literatura como fenómeno de comunicación.

2. La transmisión de la literatura.

3. Los géneros literarios: clasificación y características.

4. Características y recursos expresivos de la lengua literaria.

\section{Puntos de contacto con el Inglés}

1. Pupil's reading of simple texts shows understanding is generally accurate. In responding to a range of texts, pupils show understanding of main ideas, themes, events and characters.

2. Reading Comprehension: Identify and discuss main and recurring characters, evaluate their behaviour and justify views.

\section{2 de ESO}

1. Los géneros literarios: elementos y formas.

2. Los géneros literarios: narración, lírica y teatro.
1. Pupil's writing communicates meanig in both narrative and non-narrative forms, using appropiate vocabulary.

2. They should be beginning to use the main features of different forms of writing.

\section{$3^{\circ}$ de ESO}

1. El registro literario.

2. Obras y autores más representativos de la literatura castellana e inglesa hasta finales del siglo XVIII.

3. El contexto histórico-cultural
1. Find out popular authors and writers and use this information to select reading material by favourite writers.

2. Describe and rewiews own reading habits and widen reading experience. 


\section{Lengua y Lta. Española}

\section{4 de ESO}

1. Obras y autores más representativos de ambas lenguas a partir del XIX hasta el momento.

2. El contexto histórico-cultural.

\section{Puntos de contacto con el Inglés}

1. Write book reviews for specified audience, based on evaluation of plot, characters and language

2. Write plays scripts based on own reading, oral work, and personal experience in order to persuade and adivice.

\section{C.2. Contenidos procedimentales}

\section{Para el Área de Lengua y Lta. Española Puntos de contacto con el Inglés}

1. Reflexión oral y escrita sobre las características de la obra literaria como acto comunicativo y como producto estético y lingüístico.

2. Lectura y análisis de textos literarios de diferente forma de transmisión.

3. Identificación de los recursos expresivos, valorando su aportación a los textos literarios y no literarios.

4. Lectura comprensiva y expresiva de textos literarios en prosa y verso.

5. Reconocimiento de las características básicas del registro literario.

6. Identificación y análisis de características formales, temáticas, y expresivas de los textos literarios.

7. Lectura e interpretación de fragmentos de obras más destacadas en castellano e inglés.

8. Contextualización de los textos literarios trabajados.

9. Producción de textos de intención literaria.

10. Elaboración de opiniones propias a partir de la lectura y comprensión de textos literarios.
1. Choose and prepare poems for recital, recognising rhyme, alliterarion and other patterns of sounds that create effects.

2. Prepare, read and perform plays scripts and compare organization of scritps with stories.

3. Chart the build up of a play scene, e.g. how scene start, how dialogue is expressed, and how scenes are concluded. 
C.3. Contenidos actitudinales

1. Interés por la lectura como fuente de enriquecimiento cultural, de placer personal y de obtención de competencia comunicativa.

2. Adquisición progresiva de hábitos de lectura.

3. Valoración positiva de las obras de tradición literaria como muestra del patrimonio cultural.

4. Interés y gusto por transmitir las ideas y sentimientos propios mediante textos de intención estética y lúdica.

5. Sensibilización hacia los aspectos lúdicos y creativos del lenguaje.

6. Valoración de las producciones literarias en lengua castellana e inglesa, tendiendo a desarrollar criterios propios de selección.

\section{Bloque 4ㅜ: La Lengua y la sociedad}

D.1. Contenidos conceptuales

\section{Lengua y Lta. Española} $1^{\circ}$ de ESO

1. La diversidad lingüística en el mundo actual:
a) Principales familias lingüísticas.
b) Las lenguas románicas.
c) Las lenguas del Estado español.

2. La variación lingüística: variación geográfica.

\section{Puntos de contacto con el Inglés}

1. Uso y valoración sobre las variedades lingüísticas en el Reino Unido: inglés, escocés, irlandés, galés.

2. Our task focus on: evaluate a range of instructional texts in terms of:
a) Purpose.
b) Organization.
c) Clarity and usefullness.

\section{$2^{\text {o }}$ de ESO}

1. La diversidad lingüística en el mundo actual:
a) Procesos de formación y transformación de las lenguas.
b) Identificación de la formas diversas.

2. La variación lingüística: variación social.

3. Las lenguas en contacto: el conflicto lingüístico.
1. To demostrate their growing confidence in a range of context, pupils will be encouraged to:

a) Speak audubly and cliarly.

b) Read aloud and recite poems and raps.

c) Re-tell stories and use improvisation.

d) Choose and use relevan vocabulary.

e) Use questions forms correctly. 


\section{Lengua y Lta. Española}

\section{$3^{\circ}$ de ESO}

1. La diversidad lingüística en el mundo actual:
a) Formación y evolución del español y del inglés.
b) El área lingüística del español y del inglés.

2. La variación lingüística: variación funcional y registros de la lengua.

3. Las lenguas en contacto: el conflicto lingüístico.

\section{Puntos de contacto con el Inglés}

Ídem:

a) Focus on the main point and reply to questions appropiately usig because...

b) Organise what they say.

c) Use vocabulary and sintax to express more complex ideas.

d) Speak in a range of contexts, adapting what they say to purpose and audience.

\section{4º de ESO}

1. La variación lingüística:
a) Variación geográfica, social y funcional.
b) La lengua estándar y el registro formal.
c) El proceso de estandarización.

2. Las lenguas en contacto:
a) Procesos de normalización y substitución lingüística.
b) Situación sociolingüística actual.

1. Writing for different purposes: students will be expected to write for different purposes: recount, report, instruct, explain, persuade and discuss.

2. This can be of: formal and informal letters, news, reports, scientific experiences, stories, dialogues and play scripts. 
D.2. Contenidos procedimentales

\section{Para el Área de Lengua y Lta. Española Puntos de contacto con el Inglés}

1. Utilización y elaboración de mapas para la localización de las áreas lingüísticas del castellano y del inglés.

2. Identificación, localización y análisis de las variedades geográficas del español y del inglés.

3. Reconocimiento de la variedad estándar de la lengua castellana e inglesa.

4. Análisis e interpretación de los diferentes registros del uso de la lengua.

5. Estudio de los fenómenos derivados del contacto de las lenguas.

6. Reconocimiento de los fenómenos de la interferencia lingüística.

7. Análisis de situaciones de contacto entre el castellano y el inglés.
1. Elaboración de mapas lingüísticos sobre las variedades del inglés hablado y escrito.

2. Reconocimiento de los acentos, hábitos de pronunciación y peculiaridades del inglés hablado en las distintas partes del mundo.

3. Identify the feathers of instrucctional texts including:

a) Noting the intended outcome at the beginning.

b) Listing materials or ingredients.

c) Clearly set out sequencial stages.

d) Language of commands, e.g. imperative verbs.

D.3. Contenidos actitudinales

1. Valoración positiva del plurilingüismo y de la adquisición de competencia comunicativa en más de una lengua.

2. Valoración de la variedad estándar como la más adecuada para determinados ámbitos de uso y como muestra de unidad de la lengua.

3. Valoración de las lenguas como elementos configuradores de la identidad personal y colectiva.

4. Valoración de la continuidad de la comunidad lingüística.

5. Sensibilización hacia la situación sociolingüística en España y Reino Unido. 


\section{E. Bloque 5. La lengua y los medios de comunicación.}

\section{E.1. Contenidos conceptuales}

\section{Lengua y Lta. Española} 10 de ESO

1. La interacción de los códigos verbales y no verbales en la comunicación humana.

2. Los géneros de los medios de comunicación:

a) Géneros de prensa: noticia y la entrevista.

b) Géneros periodísticos.

3. El lenguaje del cómic.

\section{Puntos de contacto con el Inglés}

1. Importancia de la TV pública y privada en la configuración de la opinión de los británicos.

2. Prepare for factual research by reviewing what is known, what is need, what is available, and where one might search.

\section{2 de ESO}

1. Los géneros de los medios de comunicación:

a) Géneros de la prensa: reportaje y editorial.

b) Géneros de la radio: características específicas.

2. El lenguaje del cine.
1. Identificar las informaciones que se emiten desde $B B C$ radio and $T V$, and others cannals.

2. Collect information from a variety of sources and present it in one simple format sucha as a wall chart or labelled diagram.

3. Use it to bring to published from to audience, discussing relevance of layout, font, etc.

\section{$3^{\circ}$ de ESO}

1. Los géneros de los medios de comunicación:
a) Géneros de la prensa: artículo de opinión y crítica.
b) Géneros de radio y TV: géneros informativos.

2. La publicidad: características específicas.
1. Análisis de artículos, crónicas, noticias reportajes de: "The Independent", "The Times", etc.

2. About the English press:
a) Make contributions relevant to a topic and take turns in a discussion.
b) Convey ideas and share experiences.
c) Give reasons for opinions and actions.

\section{$4^{\circ}$ de ESO}

1. Los géneros de los medios de comunicación:
a) Géneros de la radio.
b) Géneros de la TV: géneros de opinión.

Idem:

a) Make plans, investigate, predic, explain report, evaluate, select and sort.

b) Start using languaje to agree and disagree. 
E.2. Contenidos procedimentales

\section{Para el Área de Lengua y Lta. Española Puntos de contacto con el Inglés}

1. Análisis de los elementos verbales y no 1. Just to read dealy press: verbales de los mensajes de los diversos medios de comunicación.

2. Reconocimiento de los géneros periodísticos de información y opinión.

a) Identify social, moral or cultural issues in stories, e.g. the dilemmas faced by characters and how they deal with them.

3. Análisis de los procedimientos de manipulación de la información y la opinión.

b) Understand how setting influence events in stories and how they effect character's behaviour.

4. Análisis crítico de los procedimientos de persuasión usados por los medios de comunicación.

5. Análisis crítico de los procedimientos retóricos verbales y no verbales en los mensajes de los medios de comunicación.

6. Distinción de los procedimientos narrativos usados en el cine y en la TV.

7. Producción de textos combinando códigos verbales y no verbales.

8. Utilización de los recursos informáticos y de las telecomunicaciones para la comunicación.

\section{E.3. Contenidos actitudinales}

1. Reconocimiento de la importancia de los medios de comunicación en la configuración de creencias y opiniones.

2. Actitud crítica hacia los mecanismos de manipulación ideológica e informativa.

3. Valoración de los medios de comunicación como fuente de información y diversión.

4. Interés por los códigos de los medios de comunicación y por su uso.

5. Interés por las tecnologías de la información y las telecomunicaciones y actitud crítica hacia su uso. 


\section{F. Bloque 6. La lengua como medio de adquisición de nuevos aprendizajes}

\section{F.1. Contenidos conceptuales}

\section{Lengua y Lta. Española \\ Puntos de contacto con el Inglés $1 \%$ de ESO}

1. Recursos léxicos: tipos de diccionarios

2. Técnicas de trabajo intelectual: lectura comprensiva, apuntes, subrayado, esquema, resumen.
1. Dictionaries: It is recommends that students use good monolingual dictionary for the majority of their work. Bilingual dictionaries and thesauruses should be available as an additional resource.

2. Students should be encouraged to keep a vocabulary notebook with interesting words with explanations, drawings and examples of use to draw from writing.

\section{2 de ESO}

1. Recursos léxicos: diccionarios especializados.

2. Técnicas de trabajo intelectual: resumen, esquema.
1. Focus on accuracy: to be fluent readers and writers students need to able to spell, produce and use grammar structures accurately.

2. Students should use familiar grammatical structures correctly in writing.

\section{3ํㅡㄹ ESO}

1. Técnicas de trabajo intelectual: las fuentes de información de la vida diaria.

2. Técnicas de trabajo intelectual: ayuda de la informática en adquisición de nuevos aprendizajes.
1. Just using internet: chatting, e-mail, and other resourcers.

2. Develop vocabulary: students should became familiar with a range of words and vocabulary drawn from texts used in class.

\section{$4^{\circ}$ de ESO}

1. Técnicas de trabajo intelectual: búsqueda de información.

2. Técnicas de trabajo intelectual: nuevos soportes y canales de la información.
1. Reading is the basis of developing cultural and language awareness.

2. Reading allows students to see structures and vocabulary in a natural way. 


\section{Para el Área de Lengua y Lta. Española Puntos de contacto con el Inglés}

1. Uso e interpretación de las fuentes de información de la vida cotidiana.

2. Búsqueda, selección y utilización de información de documentos relacionados con los procesos de aprendizaje.

3. Reelaboración de información obtenida documentalmente.

4. Desarrollo y práctica de las técnicas más habituales de trabajo intelectual.

5. Manejo de diferentes tipos de diccionario.

6. Elaboración y uso de procedimientos de recogida de información.

7. Técnicas de reescritura y manipulación de textos escritos.

8. Uso de recursos informáticos como ayuda a la manipulación y elaboración de la información.
1. Just to improve our speaking:

a) Focus on the main point and reply to questions appropriately.

b) Speak in a range of contexts, adapting what they say to purpose and audience.

c) Describe experiences and feelings.

d) Give oral presentations to the class, giving an introduction and a conclusion.

e) Reflect on their own presentation.

f) Use persuasive language.

g) Begin to use basic summary skills.

\section{F.3. Contenidos actitudinales}

1. Valoración de la función documental de las lenguas.

2. Reconocimiento de la importancia del uso de las diversas fuentes de información.

3. Precisión y rigor en la búsqueda y elaboración de la información.

4. Interés por el hábito de consulta de recursos que faciliten el acceso a la información.

5. Toma de conciencia de la importancia personal, social, cultural y académica del uso adecuado de los hábitos de trabajo.

6. Interés por el uso de los recursos informáticos y de las telecomunicaciones como facilitadores de la tarea de búsqueda y manipulación de la información.

\section{Contenidos transversales}

La LOCE y el Proyecto de Ley de la LOE -hoy ya Ley Orgánica- establecen que el objetivo primario y fundamental de la educación es proporcionar a los alumnos una formación plena que les permita conformar su propia identidad y construir una concepción de la realidad que integre el conocimiento del mundo y su valoración ética y 
moral. Esta formación ha de pretender el desarrollo de la capacidad de ejercitar, de manera crítica y en una sociedad plural, la libertad, la tolerancia y la solidaridad.

Los temas transversales son las enseñanzas que pretenden que los alumnos reciban una educación integral y maduren como personas responsables en una sociedad democrática. No constituyen enseñanzas aisladas, sino que son temas que impregnan toda las tareas educativas y se han de desarrollar en todas las áreas del curriculo de la ESO. Los temas, que se exponen a continuación, son tratados básicamente a través de los contenidos actitudinales que forman parte de los seis bloques generales antes señalados.

\section{A) Educación moral y cívica:}

Mediante el desarrollo de la capacidad comunicativa de los alumnos, estos deben valorar la lengua como un instrumento que les permite relacionarse con los otros, integrarse en el grupo social al que pertenecen, adquirir actitudes de respeto y tolerancia, aceptar diferentes puntos de vista y valorar el patrimonio cultural propio y ajeno.

B) Educación para la paz:

Mediante el lenguaje los alumnos expresan sus propias opiniones, comprenden las de los otros y se informan de los acontecimientos y problemas que afectan al mundo actual. Los alumnos tienen que adquirir hábitos de tolerancia y respeto hacia las diferentes maneras de entender la realidad y reconocer el valor del diálogo para resolver las discrepancias y confrontaciones. Han de ser personas solidarias que valoren la paz como una condición esencial para la convivencia de la humanidad.

\section{C) Educación para la salud. Educación sexual:}

A través de la lectura y comprensión de textos, los alumnos han de adquirir conocimientos y actitudes que les permitan vivir de forma saludable y relacionarse con los otros con respecto y autoestima, Estas actitudes se fomentan con el diálogo, los debates, las exposiciones, los trabajos de investigación y otras actividades.

D) Educación para la igualdad:

Este tema se ha de entender como igualdad de sexos y entre personas de diferentes razas i/o culturas. Las actividades de lectura, comprensión de textos, exposición y debate de los alumnos han de desarrollar actitudes críticas que les permitan identificar y rechazar prejuicios de tipo sexista, racista, ideológico e insertarse en la sociedad con una actitud abierta y tolerante.

E) Educación ambiental:

La lectura, la comprensión, el análisis de textos de procedencia diversa relacionados con este tema han de permitir a los alumnos alcanzar la sensibilidad necesaria para apostar por la conservación y cuidado del medio ambiente y por implicarse de forma activa en su defensa.

F) Educación del consumidor:

El análisis de textos procedentes sobretodo de los medios de comunicación permitirá que los alumnos desarrollen su capacidad crítica hacia los mensajes publicitarios y periodísticos que puedan incitar a un consumo desmesurado y nocivo para la persona. 


\section{G) Educación vial:}

Por medio del análisis de textos de la vida actual relacionados con el hábito del consumo de alcohol y otras drogas, de conducción temeraria, de infracciones, de accidentes; se trabajarán aspectos que induzcan al reconocimiento y al respeto por las normas que regulan la seguridad vial.

H) Educación profesional de base:

El análisis, la comprensión y la producción de textos orales y escritos de carácter administrativo,(instancias, curriculum, reclamaciones, contratos, entrevistas, etc), por la utilización de medios informáticos, el contacto con el mundo del trabajo a través de la prensa, el análisis de los estilos del lenguaje, y, en definitiva, el dominio de ambas lenguas los alumnos asegurarán una formación profesional de base que les permitirá insertarse en la vida adulta y laboral.

\section{Especificación de los criterios de evaluación}

Al hablar de criterios de evaluación nos referimos a cómo medir los avances en los niveles de aprendizaje que nuestros alumnos de la ESO en Sección Bilingüe van alcanzando por medio del estudio integrado de contenidos y L2, así como en relación con su propia lengua. Establecer criterios de evaluación en el modelo bilingüe de enseñanza supone articular los mecanismos necesarios para que el profesor pueda realizar el seguimiento de los niveles de aprendizaje de cada uno de sus alumnos, al mismo tiempo que comprueba la idoneidad de su metodología y de sus propuestas didácticas. Desde esta óptica se hace preciso evaluar de forma continua todo el trabajo que hacemos en clase, y especialmente aquellas modificaciones y adaptaciones que hagamos sobre nuestra propuesta curricular inicial. Además, en este proceso de evaluación tienen que participar el profesor de idiomas de forma conjunta con el profesor de bilingüe, y por descontado los alumnos.

Partiendo de estos elementos esenciales, los aspectos básicos que han de evaluarse en los alumnos que cursan enseñanzas bilingües deben centrarse en la medición de los niveles de adquisición de las habilidades comunicativas en la L2, en su capacidad para reflexionar sobre su propio uso de dicha lengua y en sus habilidades para reconocer los aspectos socioculturales que se le presentan de forma explícita e implícita con la aplicación del método CLIL en nuestras aulas bilingües. Estas tres parcelas del aprendizaje y del conocimiento lingüístico a desarrollar por el alumno han de ser medidas con criterios objetivos, los cuales se concretan en cada Unidad Didáctica del modo siguiente:

1) Comprobación de los niveles de adquisición de los contenidos lingüísticos propios del curriculum de la L1 y L2.

2) Medición de la constancia y eficacia del trabajo diario del alumno.

3) Nivel de participación del alumno en las clases de L1 y L2.

4) Grado de adquisición de las competencias lingüísticas en relación con las materias explicadas en L1 y L2.

5) Nivel de participación e integración del alumno en los trabajos de grupo. 
Estos criterios han de aplicarse teniendo en cuanta que en el modelo CLIC los resultados lingüísticos en términos de adquisición de habilidades y destrezas son el resultado lógico de que el alumno haya asimilado bien los contenidos no lingüísticos explicados en L2. En concordancia con ello, en nuestro modelo de evaluación no penalizamos las faltas de fluidez lingüística del alumno en L2, sino que más bien tratamos en todo momento de mejorarla. Y ello porque no podemos olvidar que en nuestras clases bilingües hemos de usar la L2 tan sólo hasta donde nos sea posible, pues lo esencial es garantizar que el alumno comprenda los contenidos explicados con independencia de la terminología y del método que en cada caso concreto sean empleados.

Hechas estas aclaraciones pasamos a consignar nuestra la propuesta de criterios de evaluación que se aplicarán de forma diferenciada para cada curso de la ESO.

\section{A. Criterios de evaluación para $1^{\circ}$ de ESO}

1. Habilidades comunicativas

a) El alumno identificará la información global y específica en textos orales, (exposiciones breves) sobre temas que le resulten familiares, y en textos escritos de carácter auténtico, sencillos y de extensión limitada (descriptivos), siendo capaz de predecir el significado de algunos elementos a través del contexto.

b) Participará en intercambios orales breves relativos a situaciones muy conocidas. Empleo de un lenguaje muy sencillo e incorporación de expresiones usuales en las relaciones sociales.

c) Lectura individual, utilizando el diccionario con eficacia, de textos cortos y sencillos con apoyo visual demostrando su comprensión a través de una tarea específica.

d) El alumno redactará mensajes cortos y sencillos sobre temas cotidianos utilizando los conectores apropiados y el léxico necesario para cada caso. En todo caso ha de lograr que sus mensajes sean comprensibles para el lector. Se prestará atención a los pasos que sigue para mejorar su producción escrita.

2. Reflexiones sobre la lengua

a) El alumno manifestará en la práctica el conocimiento de los aspectos formales del código de la L2 (morfología, sintaxis y fonología) tanto a través de actividades sencillas y contextualizadas sobre puntos concretos como a través de su correcta utilización en las tareas de expresión oral y escrita.

b) El estudiante inducirá las reglas de funcionamiento de la L2 a partir de la observación de regularidades en su uso y por medio de la aplicación de procesos de inducción y deducción de forma alternativa.

c) Nuestro estudiante tiene que ser capaz de establecer relaciones entre las funciones cotidianas del lenguaje, los conceptos gramaticales y exponentes lingüísticos básicos. Todo ello con el objeto de que demuestre su capacidad de utilizar los elementos gramaticales tanto en los procesos de uso como de reflexión sobre la lengua. 
3. Aspectos socioculturales

a) El alumno reconocerá los elementos socioculturales que se presenten de forma explícita en los textos con los que se trabaja.

b) Utilizará fórmulas y registros adecuados a la situación de comunicación, al interlocutor y a la intencionalidad comunicativa.

c) Mostrará aprecio por visiones culturales distintas a las propias y actitudes de respeto hacia los valores y comportamientos de otros pueblos.

d) Utilizará el conocimiento de los aspectos socioculturales que le transmite la lengua extranjera para ubicarse adecuadamente en el país de origen de la L2.

\section{B. Criterios de evaluación para $2^{\circ}$ de la ESO}

1. Habilidades lingüísticas

a) El alumno identificará la información global y específica en textos orales y escritos (diálogos y conversaciones) sobre temas que le resulten familiares y en textos escritos de carácter auténtico, sencillos y de extensión limitada (narrativos), siendo capaz de predecir el significado de algunos elementos a través del contexto.

b) Participará en intercambios orales breves, relativos a situaciones conocidas. Deberá de ser capaz de emplear un lenguaje sencillo e incorporar expresiones usuales en las relaciones sociales.

c) Leerá individualmente, utilizando el diccionario con eficacia, así como textos con apoyo visual. Leerá libros sencillos para adolescentes, demostrando la compresión de lo leído por medio de tareas específicas.

d) Redactará mensajes cortos y sencillos sobre temas cotidianos usando los conectores apropiados y el léxico adecuada a cada caso, y logrando que sean comprensibles para el lector.

2. Reflexiones sobre la lengua

a) El alumno manifestará en la práctica el conocimiento de los aspectos formales del código lingüístico de la L1 y L2, (morfología, sintaxis y fonología), tanto a través de actividades contextualizadas sobre aspectos concretos como por medio del correcto uso de las lenguas en tareas de expresión oral y escrita.

b) Inducirá las reglas del funcionamiento de la L2 a partir de las observaciones sobre sus regularidades e irregularidades.

c) Empleará términos lingüísticos básicos para referirse a los elementos gramaticales, tanto en los proceso de uso como en los de reflexión sobre su uso de las lenguas.

3. Aspectos socioculturales

a) El alumno reconocerá los elementos socioculturales que se le presenten de forma explícita o implícita en los textos con los que se trabaja e identificará informaciones culturales de tipo geográfico, histórico, literario, etc. 
b) Utilizará registros, variedades, fórmulas y estilos adecuados a la situación de comunicación, al interlocutor y a la intencionalidad comunicativa.

c) Mostrará aprecio por visiones culturales distintas a las propias y actitudes de respeto hacia valores y comportamientos distintos a los suyos.

d) Utilizará el conocimiento de los aspectos socioculturales que transmite la L2 para compararlos con los propios de la L1.

\section{Criterios de evaluación para $3^{\circ}$ de la ESO}

1. Habilidades comunicativas:

a) El alumno extraerá la información global y específica, la idea principal y los detalles más relevantes en mensajes orales (emitidos en situaciones de comunicación cara a cara o por medios de comunicación mecánica) y en textos escritos auténticos, demostrando que es capaz de realizar inferencias a partir del contexto.

b) Participará en conversaciones breves y usará las estrategias comunicativas más adecuadas para comprender y hacerse comprender y transmitir a los otros la información que conoce.

c) Leerá textos de forma extensiva y de finalidades diversas, demostrando su capacidad de comprensión por medio de ejecución de tareas concretas.

d) Redactará textos sencillos y usará para ello la gramática y el léxico adecuados, así como los recursos de cohesión que hagan compresibles sus producciones al lector.

2. Reflexiones sobre la lengua

a) El alumno mostrará habilidades para poner en práctica el conocimiento de los aspectos formales del código lingüístico de la L2 ( morfología, sintaxis y fonología) y valorará su importancia para tener éxito en la comunicación.

b) Observará las regularidades en las estructuras lingüísticas de la L2, las analizará y Ilegará a conclusiones que le permitan formular reglas gramaticales.

c) Reformulará de forma progresiva aquellas normas o reglas que se identifiquen como erróneas.

d) Identificará y utilizará distintas formas lingüísticas asociadas a la misma función del lenguaje.

3. Aspectos socioculturales

a) El alumno interpretará correctamente el uso de fórmulas, normas y comportamientos que se transmiten a través de los textos y demostrará interés por ampliar sus conocimientos de los datos culturales que se asocian con los hablantes nativos de la L2.

b) Valorará la cultura propia a partir del conocimiento de otras culturas y del contraste con ellas. 
c) Aproximará los mensajes que se desean transmitir a las características peculiares del interlocutor y respetará las diferencias de pronunciación, acento o grado de conocimiento de la L2 de sus compañeros.

d) Aplicará el uso de la L2 como medio para establecer relaciones con personas de distintas procedencias, tomando él la iniciativa para comunicarse y mostrando respeto hacia la diversidad cultural y social de los demás hablantes.

\section{Criterios de evaluación para $4^{\circ}$ de la ESO}

\section{Habilidades comunicativas}

a) El alumno extraerá información global y específica, ideas principales y secundarias en mensajes orales sobre temas familiares para él y relacionados con aspectos cotidianos de la cultura y la sociedad de los países donde se habla la L2. Ello lo hará por medio del uso de textos escritos auténticos de distintos tipos ( descriptivos, narrativos, argumentativos, explicativos), distinguiendo entre hechos y opiniones e identificando los principales argumentos expuestos por el autor.

b) Participará en conversaciones y utilizará las estrategias adecuadas para iniciar, mantener y hacer progresar la comunicación, produciendo un discurso compresible y adaptado a las características de la situación y a la intención de la comunicación.

c) Leerá de manera autónoma distintos tipos de materiales adecuándolos a las diferentes intenciones (consulta, búsqueda de información, lectura detallada, placer, etc).

d) Producirá textos escritos atendiendo a las diferentes intenciones comunicativas y respetando los elementos que aseguran la cohesión y coherencia del texto de manera que éste sea fácilmente compresible para el lector.

2. Reflexiones sobre la lengua

a) El alumno utilizará conscientemente los conocimientos adquiridos sobre el sistema lingüísticos de L1 y L2 como instrumento de control y autocorrección de las producciones propias y como recurso para comprender menor las ajenas.

b) Reflexionará sobre las regularidades y excepciones propias del sistema lingüístico de la L2.

c) Mostrará un grado suficiente de conceptualización en relación con las funciones del lenguaje, los elementos lingüísticos, los formatos y características de los textos, la cohesión y la coherencia de sus discursos.

d) Incorporará conscientemente mecanismos de aprendizaje ya utilizados (hacer deducciones, inducciones, clasificar, categorizar, formar palabras) en situaciones nuevas de aprendizaje.

3. Aspectos socioculturales

a) El alumno identificará e interpretará las referencias culturales apoyándose en claves lingüísticas y no lingüísticas que le ayuden a su comprensión. 
b) Reconocerá elementos socioculturales en las informaciones que se transmiten en los medios de comunicación sobre acontecimientos de actualidad.

c) Mostrará sentido crítico, reflexivo y respetuoso ante las diferencias de opinión que surgen de las diferencias socioculturales.

d) Valorará positivamente el enriquecimiento que otras culturas aportan a la nuestra u viceversa, apreciando las ventajas que ofrecen los intercambios interculturales.

\section{Las orientaciones metodológicas}

El planteamiento general para la enseñanza de las lenguas ha de tener en cuenta las tendencias actuales que desarrollan las descripciones funcionales de las lenguas, asî como las teorías del aprendizaje de las lenguas, destacando entre ellas las aportaciones más recientes de la psicolingüística. Estos principios teóricos han de modificar nuestra concepción sobre lo que es la lengua y la manera de enseñarla.

Alguna de las aportaciones de estas tendencias son la concepción del aprendizaje significativo y la idea de que la función primaria de la lengua es la de servir para la comunicación y el intercambio social, por lo que hemos de "procurar que existan las condiciones favorables que propicien un clima idóneo para la interacción y al comunicación en el aula", (Martínez, 2003). De la primera hay que destacar el aspecto práctico del aprendizaje y la autonomía del aprendiz. Tenemos que partir del nivel comunicativo que los alumnos hayan adquirido en la etapa anterior, de sus conocimientos previos a fin de que puedan ser aplicados y profundizados. Además la experiencia nos demuestra que se aprende más y de forma más eficaz cuando se estudia aquello que de verdad nos interesa y que son más posibles de interesar aquellas cosas sobre las que podemos actuar, y a partir de la actuación teorizar. Además el aprendizaje significativo será más y más intenso en la medida de que el estudiante gane en autonomía personal. Y de la segunda destacamos el carácter social del lenguaje.

Este CLIL pertenece a las áreas de Lengua Castellana y Literatura e Inglés, lo que supone que hemos de planificar de forma conjunta los contenidos objeto de estudio con el fin de conseguir una asimilación adecuada por parte de los alumnos y que ellos puedan lograr los objetivos comunes. Por ello todos los contenidos de ambas áreas han de programarse de forma conjunta y el Profesorado ha de tomar decisiones conjuntas sobre todas aquellas cuestiones que permitan asegurar una buena coordinación de las Programaciones y de las actividades didácticas y una buena transferencia de aprendizajes del alumno.

Las actuaciones fundamentales en cuanto a las competencias lingüísticas de base, comunes y transferibles han de permitirnos que el proceso de enseñanza-aprendizaje gane en calidad, elimine distorsiones, que permita la aplicación del curriculo de ambas lenguas de forma paralela y que capacite a los alumnos no sólo en el uso de las lenguas propias de este CLIL, sino que se incremente su disposición a aprender otras lenguas, dentro o fuera del currículum. Esta competencia lingüística de base es la que nos ha de permitir, si la aplicación del CLIL se hace correctamente, que los elementos comunes y específicos que las lenguas presentes en el currículum o en el individuo se integren como elementos de contraste y por tanto refuercen la diversificación en el modo y en el proceso de aprendizaje de ambas lenguas. 
Esta constatación, además de ser un punto de vista operativo para la concreción posterior, ha de ser una vía de ayuda al alumno si se le hace ver que el enfoque integrado de las lenguas ha de favorecer el afianzamiento de sus competencias y lo han de situar en condiciones más adecuadas para el aprendizaje de otras lenguas, dentro o fuera de la escuela. Esto implicará establecer una organización flexible, tanto en la distribución de los contenidos de ambas lenguas como en la temporalización de los mismos a lo largo de la ESO. Las necesidades comunicativas de los alumnos -tanto las que plantea la sociedad como las emanadas de los usos propios- y los objetivos a conseguir serán el punto de partida a la hora de diseñar nuestra Programación General y de Aula, las cuales han de tener en cuenta de un modo esencial los contenidos procedimentales y actitudinales.

El enfoque comunicativo del estudio de las lenguas es una propuesta o planteamiento didáctico que basa las actuaciones y el hecho de aprender una lengua en conseguir su pleno dominio. El objetivo fundamental de la enseñanza y del aprendizaje de las lenguas ha de ser la adquisición de un instrumento útil para comunicarse y para realizar otros aprendizajes. El alumno ha de adquirir una competencia comunicativa plena que le permita manejarse de una forma adecuada, tanto a nivel oral como escrito, en el doble proceso de la comunicación en cada una de las situaciones sociales de comunicación. Los principios esenciales de este enfoque se centran en conseguir la integración de todos los conocimientos incluidos en la competencia comunicativa y trabajar las cuatro habilidades lingüísticas de forma integrada partiendo de las necesidades comunicativas, escolares y sociales del alumno y de la diversidad discursiva en situaciones reales de uso.

En definitiva, se trata de trabajar el uso y la reflexión sobre el uso de las lenguas, una reflexión "estrictamente unida a la práctica inmediata", (Camps, 2001:11) Y con ello hacer del alumno un usuario competente que sepa usar ambas lenguas en situaciones y con finalidades diversas y que sepa usarlas de manera estratégica. Para ello hemos de convertir el aula en un lugar para escuchar, hablar, leer, escribir y para enseñar a autocontrolar el uso de estas habilidades. El alumno necesita razones para usar ambas lenguas y nuestra ayuda para mejorar su uso. Estas cuatro habilidades lingüísticas no son iguales ni en importancia ni de cara a su evaluación. Ciertamente, las capacidades pasivas de entender o de leer son siempre más fáciles de adquirir y consolidar que las activas de hablar y escribir. Será el contexto y las necesidades personales los que determinen la prioridad de unas u otras.

En este sentido, hemos de continuar el trabajo de comprensión oral y escrita que los alumnos han hecho en la E. Primaria. La enseñanza de estas dos habilidades tiene que ser una tarea general de todo el currículum escolar y ha de abarcar todos los niveles y área de enseñanza de la ESO.

Hemos de trabajar la expresión oral de forma sistemática. La lengua oral no puede ser considerada como un hecho que se ejercita de modo espontáneo, sino que ha de ser rigurosamente planteada y programada, trabajando tanto aspectos de corrección como de fluidez. El alumno tiene que tomar conciencia de las necesidades orales y la de aprender las pautas de conducta inherentes a las situaciones de trabajo propias de esta habilidad. Hay que partir de trabajar situaciones reales y textos auténticos de diferentes 
niveles, función y tipología textual, primando la elaboración y reflexión de aquellos mensajes más ajustados a las necesidades del alumno. Este trabajo requerirá el uso de los medios técnicos adecuados.

Para contribuir a la mejora de la expresión escrita hemos de partir de los textos más cercanos a las capacidades del alumno y trabajar en el proceso de composición de la escritura y en la relación que la expresión escrita tiene con la comprensión lectora. Con el objeto de relacionar ambas los textos procedentes de los medios de comunicación serán objeto de trabajo especial tanto por su frecuencia como por la necesidad de leerlos críticamente. La corrección de la expresión escrita no ha de ser únicamente gramatical y ortográfica, sino que ha de atender a los aspectos de la gramática textual: las propiedades de los textos.

Hemos de hacer referencia a las cuatro habilidades básicas: escuchar, hablar, leer y escribir con el fin de lograr un enfoque integrador en la enseñanza de las mismas. Hemos de trabajar cada una en cada una de las dos lenguas y hemos potenciar en el alumno las competencias comunes para evitar repeticiones, retrasos, metodologías diferentes para unos mismos contenidos. Hemos de trabajar los contenidos o diferenciados de cada una de las dos lenguas: señalar el contraste y los beneficios dados por el conocimiento divergente de ambas lenguas. La literatura ha de ser tratada como un sistema de expresión y de comunicación que ayude a desarrollar el sentido estético, crítico y lúdico de los lectores. Hay que resaltar la importancia de la literatura como discurso con características propias, el cual contribuye al desarrollo del conocimiento lingüístico de los alumnos. La literatura nos ha de proporcionar una serie de registros y ha de dar una dimensión histórica al estudio del castellano y del inglés.

Se ha de potenciar en el alumno una visión de que la literatura es un valor universal y que los productos literarios en castellano y en inglés participan de unos contenidos estéticos y culturales compartidos por otros ámbitos y por otras lenguas. En este sentido, el contacto del alumno con las principales obras literarias en castellano y en inglés, o de la literatura universal en ediciones traducidas, ha de suponer su participación de estos contenidos compartidos que forman parte de la tradición literaria universal. La literatura ha de potenciar la lectura como fuente de cultura y como fuente lúdica que proporciona placer. Por ello, el Profesorado ha de asesorar a los alumnos en la elección de sus lecturas y le ha de ofrecer muestras de las distintas manifestaciones literarias. La actividad de comentario de texto tiene que estar relacionada con el estudio de otros apartados del lenguaje.

El trabajo de profundización gramatical, (ortografía, morfología y sintaxis) ha de realizarse a partir de contextos significativos y ha de estar al servicio de un uso cada vez más rico y correcto de las habilidades comprensivas y expresivas. Nuestro trabajo en esta parcela ha de pretender la introducción de la terminología gramatical que nos ha se servir para que el alumno se mueva con facilidad en el estudio de las lenguas. Por su parte, el trabajo sobre la ortografía ha de hacerse en función de las necesidades de los alumnos y ha de partir de la detección de las dificultades más habituales en cada caso y en cada lengua. También el análisis morfológico y sintáctico ha de realizarse sobre textos y usos cercanos al alumno. 
También el aprendizaje del léxico se ha de insertar en el marco de la mejora de la comprensión y expresión del alumno y por ello hemos de trabajar la ampliación cuantitativa y cualitativa del vocabulario de todas las áreas de la ESO. Una herramienta básica de procedimiento será el uso del diccionario.

La dimensión histórica y social de las lenguas y la diversidad de registros y variedades ha de tenerse en cuenta a la hora de la Programación y la secuenciación de los contenidos. Hemos de tener en cuenta el trabajo sobre los aspectos históricos que se hace en otras áreas y a las aportaciones de la Literatura. Los objetivos planteados en este apartado se deberán tener en cuenta en el resto de los aspectos lingüísticos, y especialmente cuando trabajemos los aspectos más cultos de las lenguas. Nuestra tarea didáctica ha de transmitir una visión real de las lenguas y de su diversidad como un hecho social y como un fenómeno enriquecedor de la realidad y de las experiencias. La comprensión de esta realidad lingüística ha de ser una constante a lo largo de los cuatro cursos de la ESO.

Los temas transversales no han de ser tratados separadamente, sino con coherencia y dentro del resto de los contenidos. Hemos de trabajar a partir de las referencias propias de los alumnos mediante el análisis crítico de textos de diferentes tipos, especialmente de los medios de comunicación. Hemos de realizar reflexiones encaminadas a mejorar la autoestima del alumno y a asumir los valores de tolerancia, respeto y solidaridad. El trabajo de los contenidos procedimentales y actitudinales ha de hacerse pensando en que dichos contenidos han de servir de orientación al alumno sobre su proceso de aprendizaje. La evaluación de estos contenidos ha de tener como función constatar en el alumno la adquisición de nuevos aprendizajes, corregir sus errores y orientar al profesor sobre la adecuación de la Programación de Aula y la metodología aplicada.

El modelo de evaluación con el que hemos de medir la consecución de los objetivos ha de tener en cuenta todos los componentes de la lengua que están presentes en el diseño curricular de las áreas. La evaluación tiene que ser continua, global, coherente y diversificada. Hemos de evaluar a partir de la observación sistemática de los procesos de aprendizaje de los alumnos, dando prioridad a los procedimientos y a las actitudes, a la par que nuestra evaluación estará de acuerdo con las actividades realizadas y los objetivos fijados previamente y ha de estar adaptada a las posibilidades y peculiaridades de cada alumno.

Hemos de emplear el modelo de evaluación formativa, la cual regula los procesos de enseñanza/aprendizaje y constituye uno de los elementos básicos de atención a la diversidad. También hemos de tener en cuanta, como principios básicos de la gestión social del aula y de la atención a la diversidad, la cooperación y la interacción del alumno, su participación en la definición de los objetivos y en la concreción de los contenidos, así como la autonomía y autoregulación de sus procesos de aprendizaje.

La atención a la diversidad, (alumnos de necesidades educativas temporales que se incorporan con retraso a las lenguas curriculares, con dificultades específicas en algún aspecto lingüístico, con retraso escolar provocado por causas diversas, con motivaciones e intereses diferentes) se ha de basar en la adquisición de una competencia comunicativa que les permita desenvolverse dentro del aula y avanzar en los aprendizajes. Por ello, en aquellas situaciones de desequilibrio ha de predominar las medidas de organi- 
zación, atención y compensación, (agrupamientos flexibles, desdobles, apoyos para atención personalizada) así como las estrategias metodológicas adecuadas y elaboración de material diversificado y específico para cada tipo de dificultad. En tal sentido el Equipo Docente tiene que promover la valoración del funcionamiento de esta atención y revisar la forma regular de propuesta de mejorar.

En esta propuesta didáctica el Profesorado tiene que asumir de forma activa las funciones de coordinación, ha de dotarse de las pautas a seguir en cada paso del proceso de enseñanza y ha de discutir y consensuar con su colegas todas las medidas que se tomen para potenciar la adquisición de nuevos aprendizajes por parte de los alumnos. El profesor ha de dotar a los alumnos de una autonomía progresiva y de una responsabilidad creciente en la consolidación de sus propios aprendizajes. Para mejora la calidad de nuestra acción educativa hemos de ser críticos tanto en cuanto al método como en relación con la necesidad de contar con el análisis y la reflexión sobre nuestra propia práctica. En tal sentido nos tenemos que replantear nuestro estatus en el aula y pasar de ser el único poseedor del saber que tenemos que transmitir a ser organizadores de la actividad en colaboración con los alumnos.

\section{Capítulo de conclusiones}

No podemos cerrar nuestra colaboración sin aportar al lector algunos elementos conclusivos que el ayuden a comprender el porque de nuestro empeño por impulsar la Sección Bilingüe de nuestro IES. De entrada hemos de señalar que nuestra propuesta de Integración Curricular de L1 y L2 da respuesta a una de las sugerencias formuladas desde el documento de la U.E, titulado "Promover el aprendizaje de los idiomas y la diversidad lingüística: Plan de Acción 2004-2006"; a saber: lograr que cada ciudadano europeo tenga una capacidad de comunicación significativa en al menos dos idiomas además de su lengua materna. Recomendación que es recogida a su vez por el Consejo de Europa, organismo comunitario que insiste en la necesidad de que las personas desarrollen competencias comunicativas suficientes para relacionarse con otros miembros de países europeos, y con ello establecer un marco de referencia común para el aprendizaje de las lenguas extranjeras.

Por ello, en sintonía con los propósitos oficiales, nuestra Sección Bilingüe constituye una respuesta adaptada a la diversificación lingüística y cultural de Europa y es una muestra de nuestra disposición a cooperar en la tarea de la promoción del estudio de las lenguas extranjeras. En este sentido estamos apostando por el modelo de enseñanza bilingüe convencidos de que dicho modelo desarrolla en el alumno capacidades comunicativas útiles para el aprendizaje de las lenguas en los niveles fonético, léxico y morfosintáctico.

Con ser estas motivaciones importantes para nuestra empresa, no son las más importantes. Nosotros entendemos que el modelo de enseñanza bilingüe aporta a los alumnos de la ESO una serie de ventajas que se pueden especificar del siguiente modo:

a) La enseñanza bilingüe permite desarrollar en nuestros estudiantes sus competencias generales para el aprendizaje en un grado mayor que el alcanzado por los alumnos de las aulas no bilingües. Ello se debe a que el alumno que se somete a 
dos códigos lingüísticos desarrolla con más soltura su "flexibilidad cognitiva" manteniéndose en un permanente estado de alerta intelectual.

b) Que por la experiencia que se desprende de nuestros cursos de enseñanza bilingüe se confirma una de las opiniones que se desprenden de los estudios, investigaciones, observaciones y análisis que de este método de enseñanza hacen los expertos, a saber: que el alumno aprende mejor una L2 cuando la utiliza para aprender otros contenidos no lingüísticos.

c) Que el estudiante de la ESO que sigue el modelo de enseñanza bilingüe mejora también su dominio de la L1 y ello es posible porque ejercita sus competencias metalingüísticas al realizar comparaciones y reflexiones sobre el funcionamiento de ambas lenguas.

d) Gracias al uso regular de ambas lenguas los alumnos de la ESO ponen en relación distintas maneras de percibir y describir la realidad, con ello se fomenta su interés por otras culturas y por otras formas de pensar que existen en el mundo. $Y$ de aquí nace su sentido de pertenencia a Europa y se incrementa su tolerancia hacia otros enfoques y puntos de vista.

La concreción de estas ventajas en aspectos tangibles se sustancia en los resultados académicos que los alumnos de clases bilingües obtienen evaluación tras evaluación. Dichos resultados positivos nos confirman que el modelo CLIL ayuda a los alumnos de la ESO no sólo a adquirir una buena competencia lingüística en L2 sino a desarrollar sus capacidades congnitivas en aquellos procesos de aprendizaje que en principio le resultan arduos e inaccesibles. A partir de aquí serán el tiempo y la estabilidad de los Planes Educativos oficiales quienes nos ayuden a desarrollar en toda su extensión nuestra proyecto educativo bilingüe.

\section{Referencias bibliográficas}

Brinton, D. M. (1988). "Contend-based Language Instruction: the effectiveness of Adjunct Model" en Tesol Quarterly. Vol 22, no 4 (diciembre, 1998).

Brinton, D. M y otros (2000). "Content-Based College ESL Instruction" en Teaching English as a Second Foreing Language". Vol 4, no 4 (diciembre, 2000).

Camps, A. (2001). El aula como espacio de investigación y reflexión. Investigaciones en Didáctica de Lengua. Barcelona, Grao, 11.

Consejería de Educación. Junta de Andalucía. (2005). Borrador de Orientaciones para la elaboración del Curriculo integrado de las lenguas en los Centros Bilingües. Sevilla: Dirección General de Ordenación y Evaluación Educativa.

Consejería de Educación. Junta de Andalucía. (2005). Plan Andaluz de Fomento del Plurilingüismo. Sevilla. Dirección Gral.de Ordenación y Evaluación Educativa.

Consejo de Europa. (1996). Modern languages: Learning, Teaching, Assessment, A Common European Framework of reference. Strasbourg.

Consejo de Europa. (2001). Marco de referencia europeo para el aprendizaje, enseñanza, y evaluación de las lenguas, Estrasburgo. Trad. esp. (2002) del Instituto Cervantes. 
Cummins, J. (1999). "Research, Ethics, and Public Discourse: The Dabate on Bilingual Education", en Conference of American Association of Higher Education, Washington, D.C. March 22, 1999.

Cummins, J, y Corson, D, (1997) Bilingual Education. Vol 5. International Encyclopedia of Languaje and Education. Dordrecht, The Netherlands: Kluwer Academic Publishers.

De Arriba, C.(2003). La mediación lingüística en la enseñanza de lenguas extranjeras. Tesis Doctoral. Universidad de Barcelona.

Fernández Fontecha, A. (2001). "Una selección bibliográfica sobre el método AICLE, ( Aprendizaje Integrado de Conocimientos Curriculares y Lengua Extranjera)" en Contextos Educativos, 4 (2001).

Harris, B y B. Sherwood. (1978). "Translation as an innate skill" en D. Gerver y H.W. Sinaiko (eds): Languages, interpretation and communication. New York: Plenum Press.

Höning, H.G y P. Kussmaul. (1982). Strategie der Übersetzung. Tübingen. Gubter Narr.

Hymes, D.H. (1972). "On communicative competence"en J.B. Pride y J. Homes (eds): Social linguistics: Selected Readings. Baltimore: Penguin.

Hurtado Albir, A. (2001). Traducción y traductología. Madrid: Cátedra.

Krashen, S. (1999). "Bilingual Education: Arguments For and (Bogus) Arguments Against" en Georgetown University Roundtable on Languages and Linguistics. May 6, 1999.

March, D. (2000). Using Languages to Learn and Learning to Use Languages. An Introduction to CLIL for parents and young people. TIE-CLIL, 2000.

March, D. y G. Langé, (1999). Implementing Content and Language Integrated Learning. Continuing Education Centre: University of Jyväskylä.

Martínez, J. D. (2003). "Hacia una enseñanza de las lenguas extrajeras basada en el desarrollo de la interacción comunicativa" en Didáctica, (Lengua y Literatura), 13, 235-261.

Met, M. (1998). Curriculum decision-making in Content-based Language Teaching. Clevedon: Multiligual Matters.

Mohan, B. A. (1986) Language and Content. Reading, M. A: Addison-Wesley.

Suarez, M ${ }^{a}$ Luz. (2007). "Aprendizaje Integrado de Contenidos y Lengua Extranjera (AICLE): una de las claves de la convergencia europea" en II Jornadas Internacionales de Innovación Universitaria: El reto de la Convergencia Europea, Universidad Europea de Madrid, 21-23 septiembre.

Naves, T. y Muñoz C. (2005). "Usar las lenguas extrajeras para aprender y aprender a usar las lenguas extranjeras" en TIE-CLIL: Enseñar lenguas extranjeras. Disponible en web: http://www.tieclil.org.

Toury, G. (1980). In Search of a Theory of Translation. Tel Avid: The Porter Institute for Poetics and Semiotics.

Van EK, J.A. (1988). Objectifs de l'apprentissage des langues vivantes. Strasbourg, Vol 1. Wills, W. (1982). Übersetzungswissenschaft. Probleme und Mthoden. Stutgart: Klett. 